\title{
Using Material Culture Lessons to Cultivate Artistic Behaviors and Enrich Students' Conceptual Understanding in an Urban Middle School Classroom
}

\author{
Emily Turner
}

Follow this and additional works at: https://researchrepository.wvu.edu/etd

\section{Recommended Citation}

Turner, Emily, "Using Material Culture Lessons to Cultivate Artistic Behaviors and Enrich Students' Conceptual Understanding in an Urban Middle School Classroom" (2017). Graduate Theses, Dissertations, and Problem Reports. 6840.

https://researchrepository.wvu.edu/etd/6840

This Thesis is protected by copyright and/or related rights. It has been brought to you by the The Research Repository @ WVU with permission from the rights-holder(s). You are free to use this Thesis in any way that is permitted by the copyright and related rights legislation that applies to your use. For other uses you must obtain permission from the rights-holder(s) directly, unless additional rights are indicated by a Creative Commons license in the record and/ or on the work itself. This Thesis has been accepted for inclusion in WVU Graduate Theses, Dissertations, and Problem Reports collection by an authorized administrator of The Research Repository @ WVU. For more information, please contact researchrepository@mail.wvu.edu. 
Using Material Culture Lessons to Cultivate Artistic Behaviors and Enrich Students' Conceptual Understanding in an Urban Middle School Classroom

\author{
Emily Turner
}

Thesis submitted to the College of Creative Arts at West Virginia University

in partial fulfillment of the requirements for the degree of

Master of Arts in

Art Education

\author{
Terese Giobbia, Ph.D., Chair \\ Dylan Collins, M.F.A. \\ Kristina Olson, M.A.
}

School of Arts and Design

\author{
Morgantown, West Virginia \\ 2017
}

Keywords: material culture, contemporary art, secondary, case study, qualitative Copyright 2017 Emily Turner 


\section{ABSTRACT \\ Using Material Culture Lessons to Cultivate Artistic Behaviors and Enrich Students' Conceptual Understanding in an Urban Middle School Classroom}

\section{Emily Turner}

Within art education there is a contradiction between learning opportunities currently provided within the middle school art classroom, specifically in relation to media, and authentic contemporary artistic behavior and practice. Art educators focus instruction on traditional forms of media (i.e. drawing \& painting) while evading contemporary art and artists. Much of what contemporary art is today is represented through everyday objects/materials and educators must provide students with an opportunity to experience both inquiry and contemporary art-making through media outside of the canon. Our personal identity, culture, and reality are composed of material forms, which often go unnoticed due to the proliferation of virtual imagery and digital information. Although the integration of emerging technology within visual art pedagogy has obvious benefits to student success in a contemporary society, acknowledgment and appreciation of material culture, the tangible world around us, warrants attention. Art education has many aims, which include both exposure to contemporary art and a heightened sensitivity to the physical world in which we live.

The implementation of a collaborative material culture art project provided opportunities for middle school students to engage meaningfully in relevant cultural inquiry, as well as contemporary art making processes. Through material culture, middle school students were exposed to contemporary art, which extended beyond canonical representation reflecting the authenticity of everyday life. This study revealed how the integration of material culture into a middle school art education curricula can benefit students' understanding of contemporary art and engagement with artistic behavior.

Using case study methodology, this research investigated the effect one specific material culture art lesson had on a single class of middle school students in an urban setting in West Virginia. The purpose of this study was to examine the potential of common materials towards cultivating artistic behaviors and enriching middle-level students' perceptive and conceptual understanding in a contemporary educational context. The research questions, which framed the study included 1) How do material culture lessons promote student understanding of contemporary art in a middle school art class? 2) How do material culture lessons support artistic behavior among middle school students? 3) How do material culture lessons foster appreciation for everyday objects/materials among middle school students? The findings, resulting from the case study, appear to suggest improvements in students' understanding of contemporary art and appreciation for everyday materials/objects, as well as a comprehensive engagement with artistic behaviors. 


\section{Acknowledgements}

I would like to thank my committee members who so graciously offered their time and intellect to support and guide me throughout this intensive process. I am forever grateful for Dr. Terese Giobbia. This study would not have been possible without her expertise within the field of art education, inspiring arts education classes, and general positivity throughout this project. I would like to thank Professor Kristina Olson for her captivating Contemporary Art class, which exposed me to a depth of contemporary art I would not have otherwise known. I would also like to thank Professor Dylan Collins. Without his wealth of knowledge on contemporary sculpture and diverse materials, I would not have known where to begin.

I owe many thanks to my extraordinary parents, who have always fostered my creativity and who have never hesitated to support me in my artistic endeavors. Lastly, but not least, I would like to thank my loving husband for his unwavering support. His constant encouragement combined with his strong belief in me throughout this project fueled many long late-night hours. 


\section{Autobiographical Sketch}

This research and inquiry is consequential to my experiences as a student and artist. There was no visual arts education program during my public elementary school education. As a result of recognizing my creativity and artistic passion my parents enrolled me in an in-home arts class up the street from my house. The class catered to the parents' desire of predetermined holiday oriented master pieces which displayed technical skill beyond the students' years. When projects were dry and ready to be taken home, students relied on recognizing their name scrawled on the backside or underneath, because recognizing your piece any other way was virtually impossible. My secondary school arts classes reflected a slightly more progressive approach, but still failed to fully captivate me as an artist. To the bereavement of my incredibly supportive mother I refused to make an appointment with the art department and instead enrolled in college at the University of Tennessee as an 'undeclared' major, deciding with determination that art was not a worthy collegiate pursuit. When a new friendship led to an informal stroll through the Art \& Architecture building I was astonished by the student artwork on exhibit, and promptly applied to the program. The contemporary installations, something I had never seen before, inspired and captivated me. In 2008, I received honorable mention for the Outstanding Student Achievement in Contemporary Sculpture Award presented by the International Sculpture Center and two years later I earned my B.F.A. in Sculpture. In 2015, I eagerly continued my journey as an art enthusiast by beginning my master's in art education at West Virginia University. My experiences as a young art student, as a studio artist, and as a graduate student inform my identity as a future arts educator, as well as drive my passion for research. 
Table of Contents

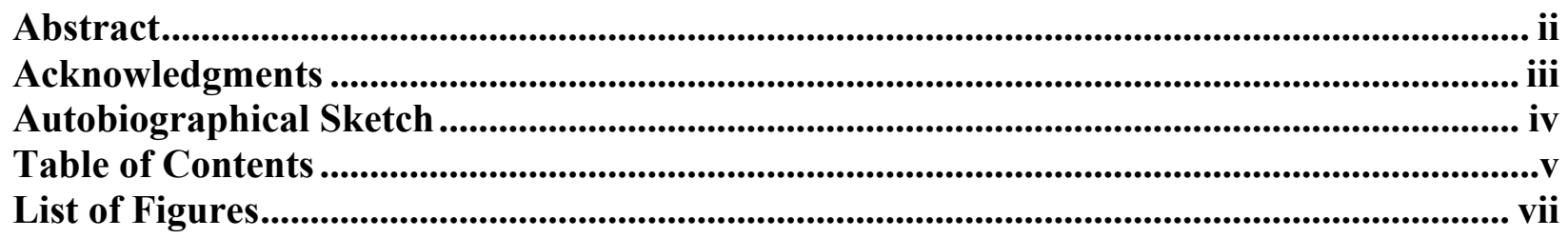

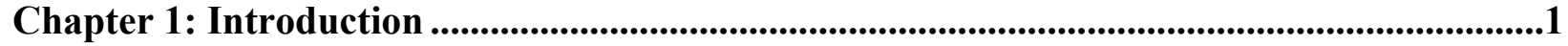

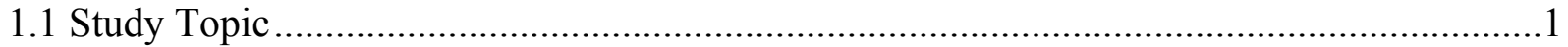

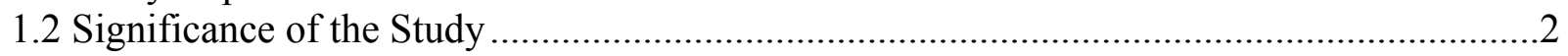

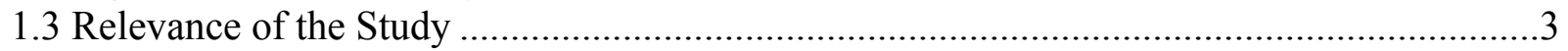

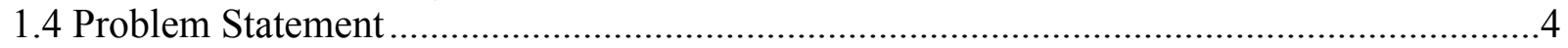

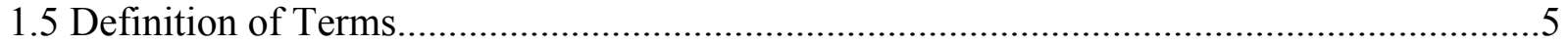

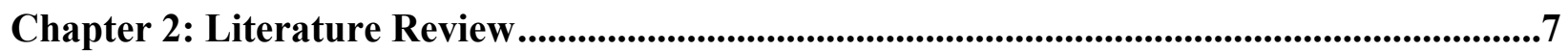

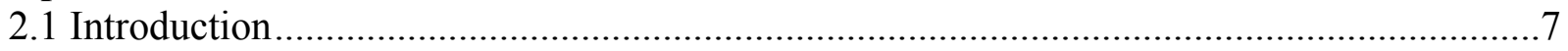

2.2 Material Culture Pedagogy Within the Art Classroom ................................................. 7

Material Culture and the Significance of Common Materials ............................................8

Visual Culture Pedagogy ........................................................................................... 10

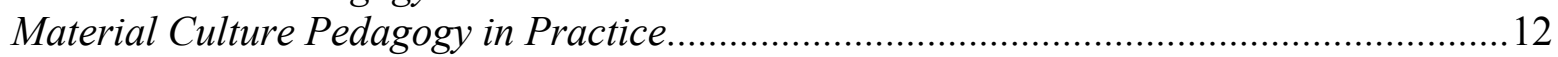

Impediments to Introducing Material Culture Art Education ........................................ 16

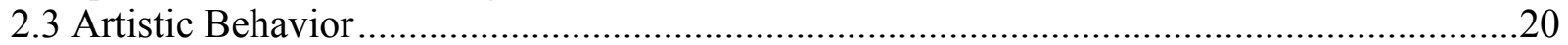

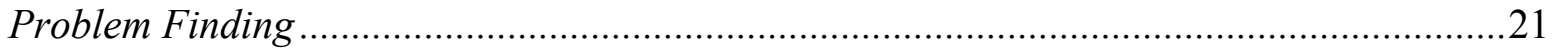

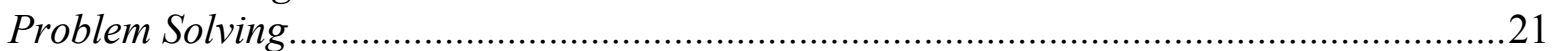

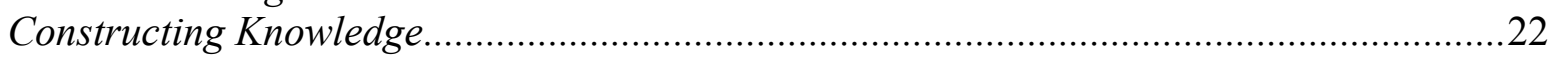

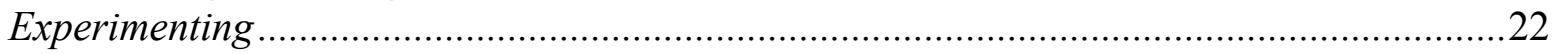

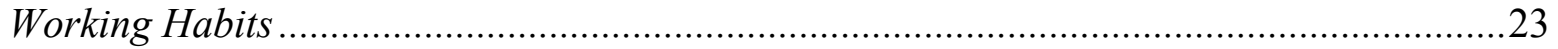

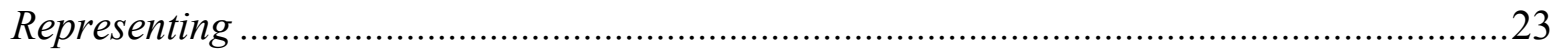

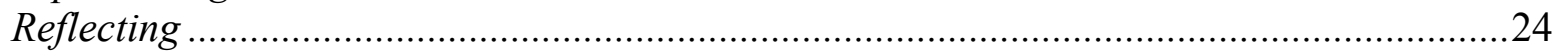

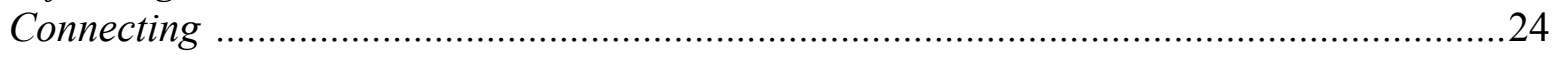

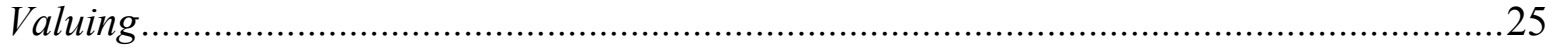

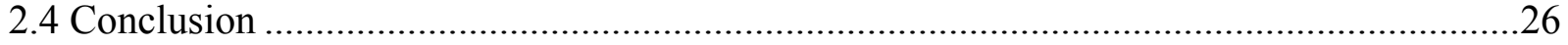

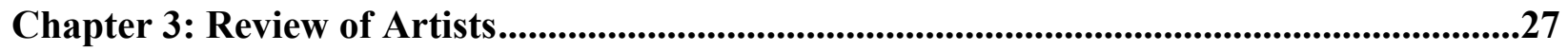

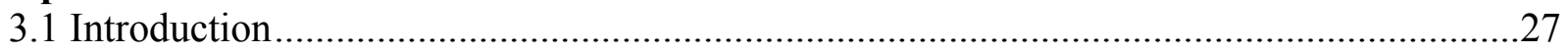

3.2 A Brief Overview of Contemporary Art Beginnings.....................................................27

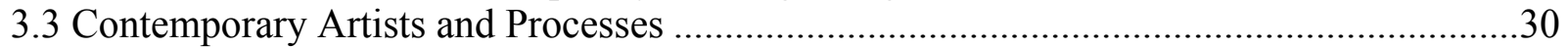

3.4 Current Discourse on Contemporary Art in Art Education ..............................................38

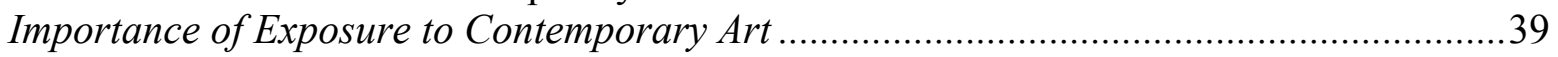

Impediments to Introducing Contemporary Art......................................................... 41

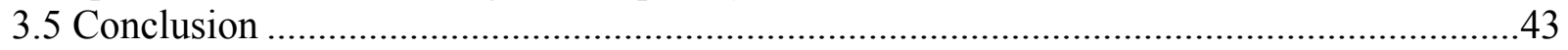




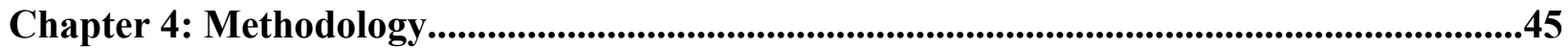

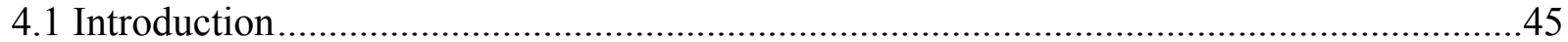

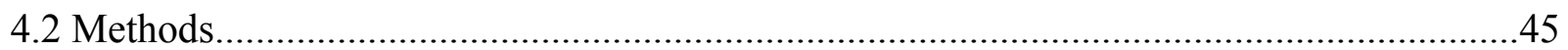

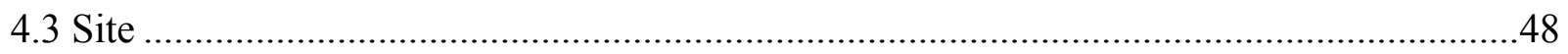

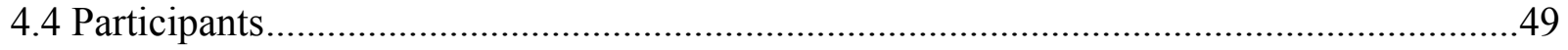

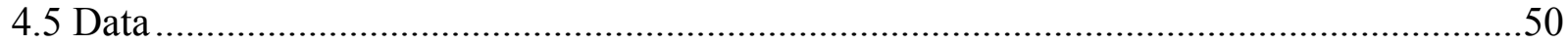

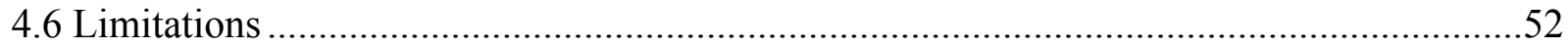

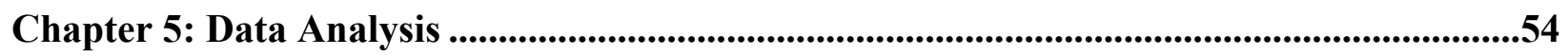

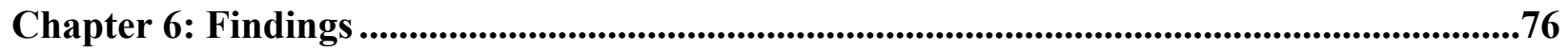

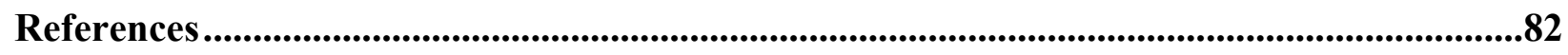

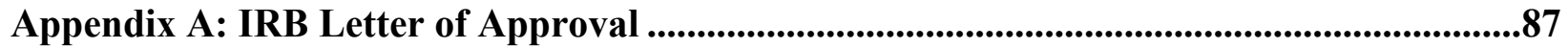

Appendix B: Consent Form .....................................................................................................89 


\section{List of Figures}

Figure 1. Fountain, by Marcel Duchamp, 1917/1964 replica.................................................. 29

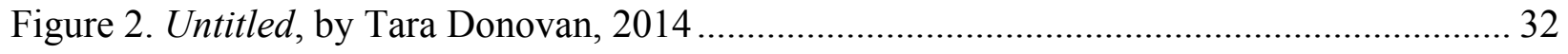

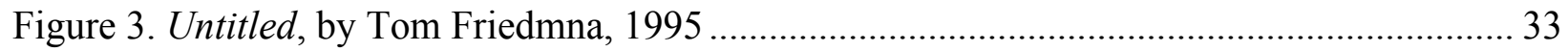

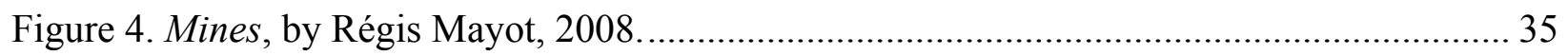

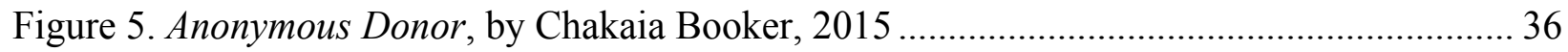

Figure 6. Color Field, by Liza Lou, 2015 .................................................................... 38

Figure 7. Collective analysis of electrical wire/cord completed through a class discussion, which I recorded on a large piece of roll paper................................................................. 57

Figure 8. Student's initial method of attaching willow vines to branches, which does not create a smooth transition from branch to 'vine' ........................................................................ 59

Figure 9. Student's solution to the abrupt connection between vine and branch. Orange extension wire is hallowed out so that it may be wrapped around the tip of the branch. The inner cords (white, black, green) are left to dangle and the orange casing is secured with yellow electrical tape.

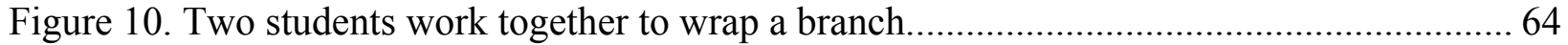

Figure 11. Several students work collaboratively to wrap the tree trunk and connect branches.. 65

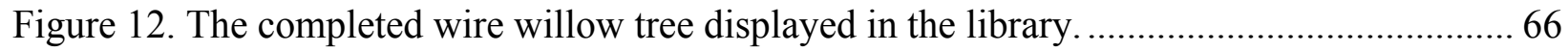

Figure 13. Detail of the completed wire willow tree, which is displayed in the library............. 67

Figure 14. Student sketch of an idea to expand the project. ............................................. 68

Figure 15. Representation implemented based on the idea presented by Student $6 \ldots \ldots \ldots \ldots \ldots \ldots . . .69$

Figure 16. Student makes connections between earrings and pain or self-confidence............... 70

Figure 17. A student wrapping a branch independently, a student recording ideas, and a pair of students co-wrapping a single branch. 


\section{CHAPTER ONE}

\section{Introduction}

\subsection{Study Topic}

There is a contradiction between learning opportunities currently provided within the K12 art classroom, specifically in relation to form and medium, and contemporary artistic behavior and practice (Gude, 2004; Thompson, 2015; Thulson, 2013). While art educators continue to focus on art-making within the canon of painting and drawing (NAEP, 2008; Pavlou, 2009), opportunities to engage in contemporary art-making processes are often neglected as teachers take ownership through traditional predesigned projects within the art classroom. However, much professional contemporary art is created using everyday objects/materials and educators should be able to provide students with an opportunity to engage and appreciate contemporary artworks and art-making.

As fewer students are exposed to contemporary artists and artwork through school organized gallery and museum visits, providing opportunities to create art with common materials may become an inexpensive and accessible way to expose students to contemporary art and processes. The purpose of this study was to examine the potential of using material culture lessons towards cultivating artistic behaviors and enriching middle-level students' perceptive and conceptual understanding in a contemporary educational context.

This study consisted of a collaborative art project with middle school students, which focused on using common materials, or material culture, in art-making. The aim of my research was to provide a rich description of one specific way in which middle school art students can engage in art-making through everyday materials cultivating an understanding of contemporary art and igniting appreciation of everyday materials and objects which surround them. The study 
sought to provide an accessible, inexpensive way to expose middle school students to contemporary art through both physical and cognitive engagement.

Material culture art lessons provide inexpensive, accessible opportunities for middle school students to appreciate and engage meaningfully with artwork and common materials, which reflect current culture. Through art analysis, class discussions, and art-making, middle school students could make connections to contemporary art and practice, which includes objects and materials from their everyday lives.

My study included 27 seventh and/or eighth grade students currently enrolled in art at an urban school in West Virginia. The collaborative project was comprised of ten, 40-minute class periods. This study demonstrated how the integration of material culture into a middle school art education curricula could benefit student understanding of contemporary art and engagement with artistic behavior.

The research questions, which framed my study were:

1. How do material culture lessons promote student understanding of contemporary art in a middle school art class?

2. How do material culture lessons support artistic behavior among middle school students?

3. How do material culture lessons foster appreciation for everyday objects/materials among middle school students?

\subsection{Significance of the Study}

The purpose of this study was to examine the potential of using material culture art lessons towards cultivating artistic behaviors and enriching middle-level students' perceptive and conceptual understanding in a contemporary educational context. This study provides art educators with a better understanding of how material culture art education may benefit middle school students in the art classroom. Furthermore, the research unveils ways to integrate material 
culture into a middle school art education curricula. Finally, this project may influence further research about material culture, artistic behaviors, and contemporary art and artists within the field of art education.

The study was significant because it confirms the opinion that exposure to the arts through material culture cultivates an aesthetic sensibility attuned to our everyday world, which in turn facilitates a cultured and well-rounded society. Lesson plans using common materials can benefit students' understanding of contemporary art, their engagement with artistic behavior, and their sensibility and appreciation for everyday objects and materials. Cultivating an aesthetic sensitivity to the world in which we live is one of many aims in art education (Dewey, 2005; Eisner, 2002). Individual students may not continue to practice art independently or through adulthood; however, art educators strive to develop a keen artistic attention or aesthetic awareness within students, towards enriching their ability to appreciate everyday life.

\subsection{Relevance of the Study}

Avoiding the disciplinary substance of contemporary art, and thus visual and material culture, within the art curricula can potentially be a disservice to the students. Disregarding contemporary art in favor of artistic examples from past centuries may unwittingly communicate that art from the students' own lifetime has no value. Art educators may evade nontraditional artmaking materials because they are reluctant and fearful of teaching contemporary art and ways of making due to their own lack of experience, knowledge, and confidence (Joo, 2011; Graham, 2010; Thulson, 2013). Relevant curricular content should include attention to contemporary culture (Gude, 2004). Unlike art that precedes the post-modern era contemporary art is often quite ambiguous and requires a way of observing which needs to be cultivated in classrooms. If 
art educators do not provide opportunities for investigating and unpacking contemporary art issues within the schools then who will? We cannot expect students to be equipped with the tools necessary for comprehending contemporary art if access to opportunities for contemporary forms of cognition and engagement are not provided; art educators must scaffold such inquiry and investigation. Additionally, art educators can further enrich investigation through student experience as contemporary art-makers, engaging in art-making processes through nontraditional materials.

\subsection{Problem Statement}

The visual arts continue to be underfunded and undervalued across our nation, and as a result, fewer K-12 students are exposed to new and emerging artists and their artistic processes within public education (NAEP, 2016). Recent reports published in 2016 by the National Assessment of Educational Progress assessed 4,400 eighth graders from across the nation and reflected a deficit in "access to arts learning opportunities" within the visual arts (NAEP, 2016, p. 31). The NAEP reported a decrease in in-class art museum field trips from 16 percent of students visiting a museum in 2008 to just 14 percent in 2016 (NAEP). Additionally, a deficit was reported in-regard-to diverse art-making materials; beyond painting and drawing. "In 2016, 66 percent of students reported that their art teacher did not have them create things out of clay or other materials in their visual arts class at least once a month, compared to 58 percent in 2008" (NAEP).

Coupled with a decline in frequency of educational museum field trips and opportunities for art-making with diverse materials within public education, this sends concern to major stakeholders such as parents and administrators who consider teaching a culturally relevant 
curriculum which exposes students to emerging artists and processes important and vital to student growth.

\subsection{Definitions of Terms}

Artistic Behavior: An inconclusive set of nine artistic behaviors which culminated from a collaborative summer workshop in 2008 between Katherine M. Douglas and Diane B. Jaquith, the founders of Teaching for Artistic Behavior (TAB), as well as other choicebased educators and researchers. The nine artistic behaviors are: problem finding; problem solving; constructing knowledge; experimenting; working habits; representing; reflecting; connecting; and valuing (Douglas \& Jaquith, 2009).

Authentic Instruction: Newmann (1993) uses the following criterion to define authentic instruction, “(1) students construct meaning and produce knowledge, (2) students use disciplined inquiry to construct meaning, and (3) students aim their work toward production of discourse, products, and performances that have value or meaning beyond success in school” (p. 8).

Case Study: A case study, as defined by Miraglia (2014), is a research methodology which "gains in-depth understanding characterized by intensive descriptions and analysis of a single unit or bounded system" (p. 303). Research involving case study methodology includes research strategies (i.e. observation or interview) and "involves an empirical investigation of a particular contemporary phenomenon within its real-life context using multiple sources of evidence" (Robson, 2002, p. 179).

Common Materials: Common materials are man-made objects, materials, things, and forms which people use, create, display, and mediate within their everyday lives. 
Common materials are all everyday items/things which are not natural to the environment, such as: fabric, buttons, dishes, paper, clothes, etc.

Contemporary Art: Contemporary art is created by $21^{\text {st }}$ century artists, those living or recently deceased, who "dynamically combine materials, methods, and concepts that challenge traditional boundaries and defy easy definition" (Learning with Art21 Guide, n.d). Contemporary art often engages viewers in participation, inquiry, and dialogue about local and global culture, as well as society.

Material Culture: The study of man-made and man-mediated objects, materials, and forms is known as material culture (Bolin, 2011).

Nontraditional artmaking materials: Nontraditional artmaking materials are materials used to create art which were not manufactured for the explicit purpose of creating art. Traditional artmaking materials are materials, which are canonical, such as: paint, ink, graphite, specialty paper, canvas, papier mache, clay, wood, stone, etc.

Teaching for Artistic Behavior (TAB): A choice-based pedagogy, founded by Katherine M. Douglas and Diane B. Jaquith in 2001, which illuminates student choice/agency through the implementation of open studio centers and a focus on teaching to the organization's nine artistic behaviors (Douglas \& Jaquith, 2009).

Visual Culture Art Education (VCAE): Visual Culture Arts Education (VCAE) is an accepted pedagogical theory centering around the notion of visual culture within contemporary society. VCAE recognizes the vast expansion of visual imagery and its effect on society and culture. However, VCAE tends to focus on two-dimensional or virtual imagery, that of advertising, mass media, television, internet, and social media (Bolin, 2011). 


\section{CHAPTER TWO}

Literature Review

\subsection{Introduction}

The purpose of this study was to examine the potential of material culture lessons towards cultivating artistic behaviors and enriching middle-level students' perceptive and conceptual understanding in a contemporary educational context. In this chapter, material culture art education will be discussed toward combating issues that inhibit a substantive and progressive art education. Then several recent case studies will be examined, as well as impediments related to the inclusion of material culture in the K-12 curriculum. Lastly, nine artistic behaviors will be defined as a framework and focus for practical and authentic instruction.

\subsection{Material Culture Pedagogy Within the Art Classroom}

Material culture pedagogy situates material culture within the framework of art education. As a curriculum framework, material culture is shared by many diverse disciplines and fields of study, and thus the definition takes on many forms throughout various domains and literature. Bolin (2011) defines the study of man-made and man-mediated objects, materials, and forms as "material culture" (pg. xi). Acknowledging the similarities and overlap between visual culture and material culture, researchers argue differentiation by highlighting a scope of material breadth and depth which visual culture fails to fully attend to (Bolin \& Blandy, 2011). Unlike, visual culture, material culture "does not privilege the visual sense over the other senses" (Bolin, 2003, p. 254). Bolin and Blandy (2011) contend that visual culture and material culture are separate domains, however they are complex systems with overlapping conceptual and material 
schemas. Thus, complete segregation makes less sense than assimilating the two or creating a confluence.

\section{Material Culture and the Significance of Common Materials}

Common materials, or man-made objects and materials, pervade our everyday lives. As a socially-constructed contextual creation; common materials create a rich fabric of meaningful material from which we constantly curate. For over 40,000 years humankind has been actively creating, collecting, and curating a vast amount of materials and objects, from tools and machinery to photographs and souvenirs. Objects and materials can depict one's power, social hierarchy, construct personal identity, or represent a tangible timeline of an individual's lifelong journey (Csikszentmihalyi, 1993; Serig, 2011). Experiencing and interacting with common materials engages our senses, memories, and emotions and actively cultivating this perception will aid in navigating our environment more holistically. Thus, material culture in the context of art education seeks to study and attend to the materiality composing our lived experiences; which becomes invisible within an increasingly digital and virtual world. This is discussed later in this chapter, however, what immediately follows is an examination of the multifaceted characteristics of raw common materiality.

Although there are publications within art education, which "directly address the importance of studying objects," they fail to address everyday common materials situated within our culture, and instead focus on museum artifacts or objects belonging within the realm of fine art (Bolin \& Brandy, 2011, p. ix). "Art education needs to approach the engagement of the senses in a way commensurate with contemporary visual culture" (Duncum, 2012, p. 182). Given the 
proper tools to harness an acute awareness of everyday life, students or learners will be able to perceive with greater aesthetic sensibility.

\section{The Senses and Embedded Meaning}

The arts have several aims and goals, which theorists and educators have illuminated in recent decades through scholarship and publications. The late arts education scholar, Elliot Eisner (2002), claimed the purpose of arts education was to enhance students' sensory awareness, aesthetic sensibility, and to promote creativity and imagination. In his writings,

Eisner discusses the importance of engaging with and fostering the senses:

As for sensibility, the arts invite us to attend to the quality of the sound, sight, taste, and touch so that we experience them; what we are after in the arts is the ability to perceive things, not merely to recognize them. We are given permission to slow down perception, to look hard, to savor the qualities that we try, under normal conditions, to treat so efficiently that we hardly notice they are there. (p. 5)

Eisner, like educational reformer John Dewey, highlighted experience as an imperative function of the arts and life. Because individuals experience the world through the senses, Eisner believed heightened sensitivity to subtleties and differences were a very important outcome of arts education. These sensibilities, along with imagination allow for the conception of new possibilities, which is important not only for individuals but also for social change. However, merely perceiving and imagining new possibilities is not enough. Representation is necessary for communication, for "stabilizing the idea" and making private ideations public (Eisner, 2002, p. $6)$.

The senses are significant and powerful within art and everyday life, and twodimensional representations, such as paintings and drawings, can never fully attend to these qualities as well as raw, tangible common materials. Paul Duncum (2012) explains, "While visual art appeals to the sense of light, both recent art and popular visual culture appeal to the 
whole sensorium, the sum total of the ways we experience the world" (p. 182). Common materials form many facets of our built environment, which include the five senses. Thus, experiencing art which uses common materials provides an easily accessibly opportunity in which students may engage in the whole sensorium.

In addition to the sensorium, people often take for granted the abstract and emotional power which one can experience through common materials, and the ability to perceive common materials beyond the obvious is a perception, which must be honed through practice.

Furthermore, meanings embedded within a specific material may or may not be obvious or significant to every individual. All man-made objects and materials are created for a specific purpose and thus contain some type of functional significance or meaning (Csikszentmihalyi, 1993). Weight, meaning, and purpose vary broadly across all man-made objects. For example, sharp weapons are specifically made to inflict pain while fluffy pillows offer support, relief, or pleasure. In addition to meanings of function and purpose common materials also embody abstract meanings relating to associations/memories, emotions, and concepts.

\section{Visual Culture Pedagogy}

Visual Culture Arts Education (VCAE) is a broad pedagogical concept, which includes popular culture as a pedagogical theory for visual arts education. Like Material Culture Art Education, VCAE acknowledges the importance of societal and contextual relevancy. VCAE recognizes the vast expansion of visual imagery and its effect on society and culture. The general acceptance and implementation of VCAE amongst arts educators has resulted in an increase in the scope of visual content within the classroom. The popularity of new media and emerging technology within research across all educational fields clearly cooperates with VCAE's 
pedagogical agenda. Additionally, emerging technology, and its multifaceted platform, is always a popular topic of research and development across educational divides. However, exploration of common materials or material culture, a sub category of visual culture, remains on the periphery of arts education practice. Many VCAE arts educators focus on popular visual culture such as advertising, digital or interactive media, icons and celebrities with little attention to tangible materiality, everyday objects, and materials. Though pop culture, advertising, and media are important to include in the scope of art education, opportunities for contemporary art-making through common materials should also be provided in a contemporary art education curricula, especially since fewer and fewer students are able to experience this type of work through gallery and museum visits (NAEP, 2016).

\section{Removal of the Arts from the Everyday Experience}

Research supports the importance of experience or practice in learning (Bransford, 2000). In the context of the arts and education, content which aims to relate to the everyday or connect with lived experience has been a topic of concern. Educational theorists, such as Dewey and Eisner, stressed the notion of art as an everyday experience by illuminating experience in and of itself as an important component to learning. In The Arts and the Creation of Mind (2002), Eisner advocates for all everyday life experiences to be perceived aesthetically, not just high art, and he discusses how the arts contribute to cognitive function, especially in regard to imagination and realized versions of reality. Eisner (2002) explains, "aesthetic experience, therefore, is potential in any encounter an individual has with the world. One very important aim of arts education is to help students recognize that fact and to acquire an ability to frame virtually any aspect of the world aesthetically" (p. 232). 
Furthermore, Dewey (2005) investigated the isolation of art objects from human's everyday experience. According to Dewey, the disconnect between art and ordinary experience is due to disorder/compartmentalization, under the illusion of order, as a result of industrialization, imperialism, nationalism, and capitalism. Concerned about the normalcy of this constructed separation, Dewey believed that the disappearance of compartmentalization would potentially allow true order, flow, and unity in all experiences. Humans yearn for aesthetic experiences and are thereby left destitute to fulfill their aesthetic hunger by cheap, pleasurable means. Dewey reminds the reader that having an experience is currently a rarity. Thus, Dewey emphasized the importance of reconnecting aesthetic forms of experience to the seemingly mundane, common experiences of everyday life (2005).

\section{Material Culture Pedagogy in Practice}

In contrast to visual culture pedagogy, the practice of perceiving and experiencing objects, materials, and artwork deeply is an important goal of arts education and must be cultivated in the classroom through opportunities and experiences. Many art educators utilize materials as a strategy towards encouraging critical and conceptual cognition and representation, as well as motivation, amongst students (Blandy \& Bolin, 2012; Douglas \& Jaquith, 2009; Franco, Ward, \& Unrath, 2015; Grodoski; 2016; McElhany, 2017).

Grodoski (2016), a middle school art educator, does not specifically focus his study on 'material culture', however, he utilizes unpacking/packing strategies to support student inquiry of everyday objects and ambiguous art. Grodoski (2016) describes unpacking/packing as, "a five-part framework that challenges students to categorize and analyze the description, emotion, reference, and audience of a work of visual culture, then synthesizing theses aspects into a theme 
with further questions" (p. 21). Unpacking/packing, an expanded alternative to Visual Thinking Strategies (VTS), scaffolds learning by beginning with everyday object inquiry before moving to contemporary works of art. Thus, the strategy highlights the importance of everyday objects as a basis for interpreting and creating meaningful artwork, as well as perceiving and appreciating contemporary art. Unpacking is an excellent starting point when investigating and interpreting material culture; a strategy I incorporated into this study. However, though the strategy facilitates inquiry into everyday objects and examines contemporary three-dimensional art the study only provides examples of student production through traditional drawing and digitally manipulated artworks. Furthermore, the creative problem grid utilized for packing specifically dictates the emotion, audience, references, and metaphors which students must represent within their artwork. The grid, which is numbered, relies on the student's phone number to determine each categorical option, he explains, "students write their last five digits of their phone number across the column header to determine which aspects of packing will become their problem parameters" (Grodoski, 2016, p. 25). Although this method dictates the theme, students may still construct personal meaning which aligns with the themes given.

Several arts education researchers have found the use of everyday objects and materials successful for allowing students to represent their identities and ideas. In one study, middle school art teacher Jacqueline McElhany (2017) reflected on her teacher-designed art assignments and implemented changes, which allowed students to choose their own found materials through an open-ended mask making project. She admits that the eighth graders were skeptical at first, because they were not used to such freedom, however, the teacher discussed the importance of embracing failure. Additionally, she modeled the exploration based on process of found object sculptor Nick Cave, about whom the students had watched a video about. McElhany's alterations 
to her teaching style resulted in student art which embodied "meaning and substance" (2017, p.

33). She explains, "They were not carelessly putting objects together just to finish the project, but truly articulating themselves. Their masks shared personal narrative, expressed emotions, and revealed strengths and weaknesses. They became active forms of communication inviting the viewer to experience the student's life story” (p. 33). For example, McElhany (2017) asked a student to explain the meaning found in a small, decorative wooden bird attached to their artwork the student provided a layered response. He first tied the bird to his and his mother's love of nature but then states, "it also shows how I wish I could just try to fly away from all my mistakes because it kind of like embarrasses me in a way" (as cited in McElhany, 2017, p. 33). Thus, McElhany (2017) found that the accessibility to found materials ignited student exploration, and that this caused them to "dig deeper and find new ways to convey their personal voices" (p. 34).

McElhany's students were give material choice, and her study shows that students were able to meaningful connect and convey their identity through chosen materials. However, both the end-product and the theme (identity masks) were predetermined by the educator.

Another recent study utilized assemblage thinking as a mixed-media strategy for representing individual identity and community culture (Kee, Bailey, Horton, Kelly, McClue, and Thomas, 2016). Kee et al. (2016), a collective of arts educators and researchers, used "collaboration as creative assemblage" with K-12 students in which students represented their identities through manipulated suitcase assemblages (p. 14). The art education researchers running the program provided the students with a suitcase as a base for which to represent self, community, and culture through raw materials. Kee et al. (2016) found that "when experimenting with these art forms, students develop skills as curators of their own identities, selecting materials and images from their everyday lives and discussing how they might clash, interact, 
and collaborate into an artistic whole" (p. 15). For example, several students from New Orleans, Louisiana incorporated "Mardi Gras beads of the characteristic colors of purple, green, and gold to display their heritage" (Kee et al., 2016, p. 18). Kee et al. (2016) also found that students were able to "construct their own forms of knowledge" through the selecting of materials, which is described as a "cognitive and creative processes that informed their work, and the narratives told about their artworks and identities" (p. 17-18). Their exploratory study of unpacking identities found that "with its open-ended and personalized products and processes, assemblage can be a transformative community-building practice in the arts classroom” (Kee et al., 2016, p. 19). Furthermore, researcher James McClue (2015) states:

The notion that creative intelligence and behavior are a collective practice is absolutely critical. If it takes a village to raise a child, why wouldn't it be pertinent to believe that it would not take a learning community to educate a student? It would behoove educators and students alike to concede that intellect and performance are a collective application. (p. 19)

Thus, the facilitation of a collective community of artists proved significant within the study. However, each student produced their own individual identity suitcase, so the collective was focused on sharing ideas, techniques, and constructive criticism rather than representing the process of contemporary collaborative installation. Furthermore, form and theme were once again predetermined elements, as the idea of identity suitcases was designed specifically by Kee (2016).

Each of these studies highlights different methods of exposing students to material culture, and are thus progressive. Even so, they each seem constricted by more than one factor of predetermination. Though these three studies are certainly not exhaustive, they reflect a trend. There appears to be a need for more research on less predetermined open-ended projects that expose material culture to middle school students. 


\section{Impediments to Introducing Material Culture Art Education}

Curricula which addresses material culture by providing opportunities for art-making with common materials may be beneficial, however, there are issues which may impede its implementation. Three-dimensionality, non-traditional materials, and the proliferation of technology are addressed as critical issues, which may interfere with opportunities for contemporary art-making within the scope of material culture art education. Acknowledging these issues informs concerned educators and provides an opportunity for them to manage future implementation of material culture more readily. The implementation of material culture is important because it allows more opportunities for students to access diverse materials, as well as contemporary strategies and processes.

\section{Issue of Three-Dimensionality}

Student access to three-dimensional learning opportunities are disproportionate to those of two-dimensional learning opportunities, therefore much is to be learned from students gaining access to three-dimensional art-making (NAEP, 2008, 2016; Pavlou, 2009). "Certain children are concrete three-dimensional thinkers caught...in a paper and pencil desert!” (Douglas \& Jaquith, 2009, p. 67). Hypothetically, if one were to stumble into a public middle school art classroom one would observe drawing or painting as the prominent form of artistic representation (NAEP, 2016). According to the National Assessment of Educational Progression report on visual arts, two-dimensional artwork seems to dominant art education curricula $(2008 ; 2016)$. Why is this the case? If you ask a teacher, they may offer several rationales: 1) Space, both in respect to working space and storage space; 2) Lack of confidence in students' abilities to engage with materials; or 3) Personal inexperience, and thus scant professional confidence, with threedimensional engagement or implementation (Douglas \& Jaquith, 2009; Pavlou, 2009). Victoria 
Pavlou (2009) conducted a case study which examined young children's three-dimensional artmaking capabilities and teachers' preconceived notions of young children's three-dimensional artmaking potential. Her study provided evidence supporting young children's ability to represent and express ideas within three-dimensions. As for the educators, Pavlou (2009) explains:

The domain of three-dimensional representation has not received much attention and little is know about children's development in this form. Thus, it is not surprising that early childhood educators' training often lacks reference to children's artistic development in three dimensions. As a result, many early childhood educators tend to underestimate children's potential in three-dimensional art-making and consequently limit children's access to three-dimensional representations by given preferences to twodimensional graphic mark-making. (p. 140)

Douglas and Jaquith (2009) remind us of students' developmental considerations when first working in three-dimensions by stating that they "may look no more organized than a three-yearold's scribble, but are just as necessary and valid as those early marks with crayon or maker", and she goes on to highlight practice, which is critical to developing and improving technical skills (p. 72-73).

Although Pavlou provided critical insight as to why educators may avoid threedimensions the study centered on a malleable material — mod art, rather than everyday objects and materials related to material culture. Traditional types of sculptural materials are still largely used in the art room, so when projects consisting of three-dimensions are included in the curricula they are often ceramic/clay or another more traditional malleable material (Douglas \& Jaquith, 2009; NAEP Arts Assessment, 2016).

\section{Issue of Nontraditional Art-making Materials: Common Materials}

Material freedom is one critical characteristic of contemporary art-making processes due to the frequency of its use as a strategy for conceptual meaning making. Merely presenting 
students with contemporary artworks as inspiration for art-making, and dialogue is not sufficient to teach authentic contemporary artistic behavior. Allowing students to create conceptual meaning through non-traditional art materials, with teacher scaffolding, is potentially the next step towards broadening students' understanding of the visual world, as well as contemporary art being produced today. "Adolescents need guidance in understanding abstract concepts, and art teachers play an important role in helping students see the relationships between materials and ideas--- not only in the analysis of artworks, but also in the process of their own art-making" (Perkowski, 2015, p. 32). Providing an opportunity for students to create meaningful artwork through contemporary/untraditional art materials becomes an important part of this process. Using contemporary art materials will promote intentional meaning making and encourage attention to concept (McElhany, 2017).

While facets of student-centered and choice-based pedagogies are practiced in many art classrooms across the country student agency and choice are rarely encouraged in relation to material (Douglas \& Jaquith, 2009). The omission of material choice in all artmaking endeavors, or the opportunity to employ the significance of materials' conceptual properties, does not reflect artistic habits (known generally as expert practices) which novice students could cultivate and apply toward transfer to other domains of artmaking (Bransford, 2000). Everyday objects and materials provide an opportunity for purposeful and conceptual meaning making due to the inherent meanings imbedded within them, as materials are frequently used by contemporary artists as a strategy for conceptual meaning making.

\section{Issue of Technology}

One contributing factor, which results in the neglect of materiality, is the hyper focus on the incorporation of emergent digital technology across all academic disciplines. Technology 
increasingly permeates everyday life in ways never imagined. Many forms of contemporary art are virtual representations and many arts educators utilize various software programs as an alternative approach to traditional forms of media. Freedman (2003) discusses technology's impact on the arts, how it has "caused us to reconceptualize previous art," by illuminating photography's impact on painting through Photorealism (pg. 128). Freedman (2003) goes on to say, that "technological imagery blurs the boundaries between truth and fiction by acting as both....at the same time, pervasive images of violence enabled by newer technologies desensitize them to reality" (p. 129). While technology certainly elevates many facets of learning and is one form of contemporary art/making other ways of thinking and creating should be both explored and practiced within the classroom. Attention to our built environment is especially critical in a society when children's allotted "screen time" is a major concern for parents, guardians, and educators. Freedman (2003) highlights issues with technology among adolescents, especially television, such as: the "sheer amount of time children spend viewing;" the lack of quality control; the inability to differentiate fiction from reality due to children's "little firsthand experience with the world"; the influence of violent behavior; and the cultivation of "sexist and racist attitudes" (p. 144).

\section{Summary}

Visual culture art education provides critical opportunities for investigating popular culture, advertising, and the media and though it aligns with many types of contemporary art it fails to fully address material culture. Material culture art may prove more inclusive as common materials provide a depth of experience, both tangible and intangible, unmatched by a virtual world. People often take for granted the abstract and emotional power which one can experience 
through common materials, and the ability to perceive common materials beyond the obvious is a perception which must be honed through practice. Contemporary art represented through common materials allows students to access opportunities for cognitive experiences which may cultivate an appreciation for everyday objects, as well as engage in contemporary art-making processes. Technology can and should be utilized advantageously toward student learning, and it does shape much contemporary art, however, arts educators should not neglect attention to our built environment, raw materials, or common materials in teaching contemporary art and artistic behaviors.

\subsection{Artistic Behavior}

Artists work in numerous ways and are specific experts within their own unique domain, so rather than teach one way of working arts educators often focus on general habits or behaviors which encompass the essence of artistic practice or process. "Process, an umbrella term referring to myriad ways in which an artist, works, becomes more clearly defined through repeated actions" (Douglas \& Jaquith, 2009, p. 2). These repeated actions, which shape and inform artistic process, are known as 'habits of mind' or 'behaviors'. Curricula which focuses attention on unveiling the working habits of experts is acknowledged within the field of education as best practice, because facilitating and scaffolding opportunities for novices to learn how and why experts engage in practice is crucial to learning retention and knowledge transfer (Bransford, 2000).

Studies within arts education have culminated in the development of several categorical representations of artistic habits/behaviors. When the eight Studio Habits of Mind were developed in 2008, the authors admitted they modeled it after Eisner's own artistic practice 
(Eisner, 2002; Hetland, Winner, Veenema, \& Sheridan (2013). The founders of the Teaching for Artistic Behavior (TAB) ideology, collaborated with other choice-based researchers to provide a list of nine artistic behaviors, those being: problem finding; problem solving; constructing knowledge; experimenting; working habits; representing; reflecting; connecting; and valuing. Though no one set of habits/behaviors is entirely inclusive, for this study, I adopted Douglas and Jaquith's artistic behaviors as a framework for which to focus my perspective and instruction, as well as to provide categorical organization during data collection and analysis.

\section{Problem Finding}

Not to be confused with problem solving, problem finding, relates to logical induction rather than deduction. Douglas, Jaquith, (2009) and their research group recognize problem finding behavior in students who "identify questions, research, visualize possibilities, and think divergently" (p. 4). Finding problems is an artistic behavior, which most resembles creativity due to envisioning or originating meaning, questions, or representations from naught. When educational stakeholders claim to desire curriculums, which cultivate and foster 'problem solvers' they likely mean 'problem finders', as divergent and dynamic cognitive ability, or creativity, is the golden egg of art education.

\section{Problem Solving}

Solving problems in likened to creativity as well, though not wholly as the problem already exists. Problem solving is recognized in students who "revise, refine, or reinvent ideas; intuit; infer and understand; and ponder” (Douglas \& Jaquith, 2009, p. 4). 


\section{Constructing Knowledge}

Constructing knowledge is reflected when students "apply concepts to work" or synthesize understandings in new situations” (Douglas \& Jaquith, 2009, p. 4). Baxter (2014) reminds us, "it is vital for art educators to consider that artmaking is reflexive and iterative, that it is an act of social justice, and is the construction of new knowledge as well as a process of meaning-making" (p. 33). Art educators often report students' inability to adequately express the meaning behind their artwork, so attention to constructing knowledge toward understanding the why or meaning behind personal works is critical (Berk, 2015; McElhany, 2017).

\section{Experimenting}

Experimenting or "playing, a necessary component of any creative process, is the first (and foundational) principle of possibilities that can emerge from a quality art curriculum" (Gude, 2010, p. 35). To "play, improvise, explore media, and innovate" are all ways of experimenting, which hark back to elementary art practice (Douglas \& Jaquith, 2009 p. 4). Eisner (2002), as well as Dewey, often stressed the desire for arts educators and parents to cultivate and sustain young students' playfulness, imagination, and "exploratory delight" through the arts (p. 5). However, too often art projects are started without a planned period of play, but rather a mission in mind or a teacher-designed product (Hathaway, 2013; McElhany, 2017). Experimentation and play are importance facets of artistic behavior, yet Olivia Gude (2010) reminds us, "although it may seem counterintuitive, a creativity curriculum must be structured to teach methods of practices of playing with elements and concepts" (p. 36). The outcome of artistic experimentation is highlighted by McElhany’s (2017) findings, “when students are 
encouraged to explore, they dig deeper and find new ways to convey their personal voices" (p. 34).

\section{Working Habits}

Working habits are the basic procedures performed before, during, and after creating art. Sketching, setting goals, collecting materials, discussing, collaborating, revising, and perseverance are some, but certainly not all, of the working habits of artistic behavior. Collecting, for example, is an often-overlooked facet of the artistic process, but the source of a collection varies, which informs meaning. For instance, some artists purchase materials online or through stores, others scavenge on the streets, and yet other artists mine sources which are personal, such as Maya Lin who used her father's glass marble collection in her installation Folding the Chesapeake (2015) at the Renwick. Working habits may seem comparatively insignificant to more abstract artistic behaviors, but they can bear significance.

\section{Representing}

Representing, which is the basics of art, is to "observe, compose, express, communicate ideas visually, represent a point of view, and/or develop style” (Douglas \& Jaquith, 2009, p. 4). Many K-12 students view expressing oneself as the definition of art. It seems little thought is given to questioning, exploring concepts, or researching, which are major facets of an artists' actual behavior/practice. 


\section{Reflecting}

Reflecting, a challenging notion for students, is further defined as to, "perceive, question, interpret...apply understandings, and find meaning” (Douglas \& Jaquith, 2009, p. 4). Studies in the visual arts report deficiencies regarding students' ability to verbally communicate conceptual meaning within their artworks (NAEP, 2008; Berk, 2015; McElhany, 2017). This challenge reflects a deficiency in critical thinking and cognitive capacity among students in secondary schools. "Big Ideas" or "Focuses" are stressed across educational domains because meaningful concept rich curricula are critical toward authentic student learning (Bransford, 2000). In art education, we are taught to not simply include, but incorporate a "Big Idea" into every lesson we design, as well as a conceptual objective. Why? Because artistic processing/production, which is conceptually rich and mindful does more for students, and ultimately society, than the ability to simply shade an apple, a "school art style" exercise, which only requires technical skill (Efland, 1976; Thulson, 2013; Dewey, 2005).

\section{Connecting}

Making associations, analyzing artwork, recognizing interdisciplinary relationships, and cultivating empathy are all ways of connecting (Douglas \& Jaquith, 2009). On one level, connecting can be a schematic way of aligning prior knowledge with new or emerging concepts, or knowledge transfer (Bransford, 2000). On yet another level, connecting may mean an emotional, relational, or cultural recognition of similarities or understandings. 


\section{Valuing}

The last of the artistic behaviors, valuing, is to, "embrace freedom, appreciate ambiguity, open up to possibilities, and make choices" (Douglas \& Jaquith, 2009, p. 4). Valuing is a significant behavior in the context of contemporary art curricula, as contemporary art is ambiguous in nature and requires a degree of openness for perception and appreciation.

\section{Summary}

This list of behaviors is not exhaustive or entirely inclusive, however, they adequately attend to the behaviors and habits of working artists and teaching novices. Art educators must attentively delve deeper than simply creating art, or representing. Time away from creating products must be allotted to engage in meaningful play, questioning, research, and appreciation. As Art21, a nonprofit educational organization which produces film series and internet resources on $21^{\text {st }}$ century artists, so aptly suggests, "talk more make less" (Learning with Art21 Guide, n.d.). If we expect to make gains in student learning in terms of conceptual understanding we must allot time for discussions, reflections, analyzing, inferring, and constructing knowledge. Providing opportunities through authentic instruction for novice students to engage with these nine diverse artistic behaviors, which include cognitive exercises in addition to physical practice, will benefit student learning. Studies support that teaching expert habits of mind, in this case artistic behavior, will result in heightened retention, deeper understanding, and a greater ability to transfer skills and knowledge (Bransford, 2000). 


\subsection{Conclusion}

The art classroom is abundant with opportunities to engage students in meaningful artmaking experiences, which connect students to their everyday lives. Educators understand the importance of personal experiences, history, and context in relation to learning and meaning making. However, the understanding of contemporary art-making processes is increasingly harder to grasp when the arts are so undervalued and underfunded. Students are less and less exposed to contemporary art through school organized field trips to galleries and museums as funding dwindles. A curriculum which focuses attention on material culture can create opportunities for contemporary art-making without relying on additional funding. Common materials are readily available and inexpensive, if not free, to gather and collect. This review of literature does not serve as an argument against traditional art but rather focuses on the importance of engaging learners with diverse common materials, which may cultivate their understanding of art made within their culture and during their lives. 


\section{CHAPTER THREE}

\section{Review of Artists}

\subsection{Introduction}

Many contemporary artists represent ideas through common materials; giving them new life and function. Museums and galleries have broadened their curatorial scope allowing for exhibitions which may have previously been deemed low-art; involving common materials or craft. This chapter begins with a brief overview of contemporary art and its beginnings, which provides a foundation for current and progressive art education discourse. A small selection of contemporary artists and their art-making processes will be examined, because such an understanding is vital toward understanding artistic behaviors in a contemporary educational setting. The exhibitions Manufractured: The Conspicuous Transformation of Everyday Objects (2008) at the Museum of Contemporary Craft in Portland, Oregon and Wonder (2015) at the Renwick Gallery in Washington, D.C. informed much of my investigation and shaped the selection of artists discussed throughout this section. Lastly, the importance and impediments of exposing students to contemporary art will be further investigated.

\subsection{A Brief Overview of Contemporary Art Beginnings}

Since the emergence of contemporary art in the 1960s, notions of what constitutes art has progressed. Several boundaries within visual arts have been blurred and broken in reaction to modernism, which held tightly to conventional categorization of media. Traditionally art has been created, labeled, and well defined within specific media categories, such as: painting, drawing, printmaking, sculpture, etc. However, several movements emerged following 
modernism which worked to destabilize the strict compartmentalization of visual art, such as:

Dada, Pop, Fluxus, Minimalism, and Conceptualism.

Dadaist Marcel Duchamp (French-American, 1887-1968) was credited with breaking the first major barrier between modernism and contemporary art through his readymade piece, Fountain (1917/1964). Heartney (2008) summarized the complexity of his influential work in writing:

On one hand, Duchamp's gesture can be read to mean that anything is art-even, in the right circumstances, the humblest manufactured object. This reading has inspired any number of artists who have unabashedly employed found objects in the creation of high art. But...Duchamp himself preferred to see his readymades as proof that art is in fact no different from anything else in the world. Instead of elevating the commonplace, this interpretation casts art off its pedestal and into everyday life. (p. 41)

Duchamp's Fountain (Figure 1), a signed and dated porcelain urinal, actively criticizes the hierarchical object categorization perpetuated by institutions; such as art galleries and museums. Regardless of the intended purpose of Duchamp's urinal, it is the model for artists who unapologetically created art from common materials elevated into the realm of fine art. Heartney (2008), maintains, "there is no question that the history of modernism and the evolution of art today are unimaginable without him...blurring the boundary between art and life, Duchamp set the stage for much of what was to come... and the infusion of materials and forms that were previously foreign to art" (p. 40-41). 


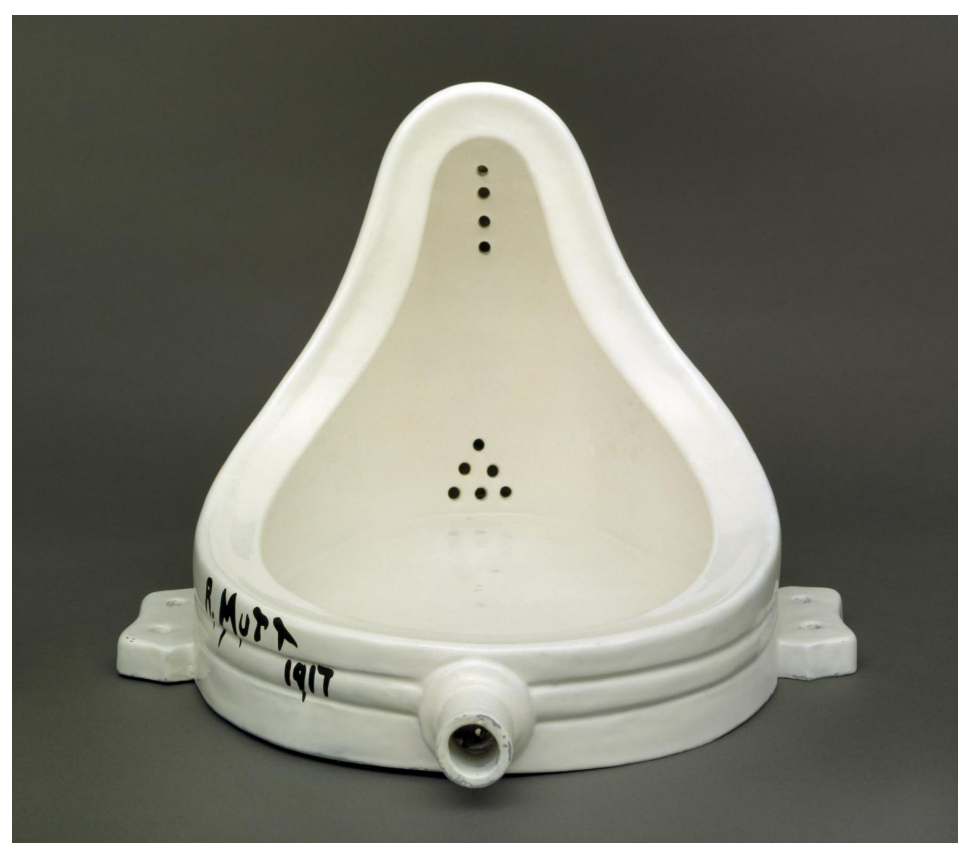

Figure 1. Fountain, by Marcel Duchamp, 1917/1964 replica, porcelain urinal. Retrieved from http:www.tate.org.uk/art/artworks/duchamp-fountain-t07573. Copyright Succession Marcel Duchamp/ADAGP, and Paris and DACS, London 2017.

Robert Rauschenberg, Roy Lichtenstein, Claes Oldenburg, and Andy Warhol were major players in dissolving boundaries between art and everyday life, as well (Danto, 2009). The works created by these artists questioned traditional notions of fine art, breaking away from an elitist perception of high art by elevating the everyday and the ordinary. The illumination of the everyday within art, which was done through recreation and/or enlargement of objects, the literal use of objects, and comics facilitated a greater accessibility to the arts for society. "This situation of radical pluralism put an end to the creation of movements and raise, in an acute form, the question of what the philosophical definition of art could be” (Danto, 2009, p. 20). Danto (2009) summarizes the contemporary state of the arts due to the dissolving of barriers and boundaries and the notion that anything can be art by stating, "the frontier is everywhere" (p. 20). 


\section{Summary}

Contemporary art refers to the art of the here and now, and reflects a break from the binds and boundaries of tradition. Due to the rapid advancement of technology, and the internet, art today is more global than ever before and embodies many forms. Though some contemporary art is still created by traditional processes through traditional canonical media/materials a large majority of contemporary art is not. Contemporary art is knowingly ambiguous, open-ended, and embraces the notion that viewers are active participates in the creation of the artworks' meaning. Today artists express and represent ideas and meaning through various media outside of the traditional canon, such as: sound, performance, happenings, light, video and digital art, and everyday objects/materials.

\subsection{Contemporary Artists \& Processes}

Steven Skov Holt and Mara Holt Skov's Manufractured (2008) presents a rich visual and textual investigation of how many contemporary artists work with common materials. Holt and Skov (2008) use their catalogue to highlight ways in which form follows processes, such as: “dissection, fabrication, accretion, fusion, provocation, subversion, infection, variation, manipulation, ornamentation, and perception" (p. 7). This list is not exhaustive, but it provides categorical chunks to viewers in which to aid in further analysis of varying processes. There are still yet other artistic strategies to consider when examining artists who mediate common materials, such as appropriation and juxtaposition, which have more to do with conceptual placing rather than physical process. For example, Olivia Gude (2004) also presents a categorized list, culminating from her work with the Contemporary Community Curriculum Initiative (CCCI), of visual and conceptual principles, which contemporary artists employ, they 
are: “appropriation, juxtaposition, recontextualization, layering, interaction of text \& image, hybridity, gazing, and representing” (p. 9-11). Both Skov's and Gude's lists are not exhaustive, as they only represent two such ways of categorizing contemporary artists' strategies and processes; there are many more. Even with such categories artistic processes and strategies often overlap and boundaries are hard to define, which reflects the attitudes of the boundary breaking artists who combatted categorization or compartmentalization.

The Wonder (2015) exhibition includes "works where part of the fascination is not just the concept, or the visual beauty, but the sometimes startling mechanics of how it came to be," the installations "focus on labor, process and materials, with an eye always to the contemporary" (Bowley, 2015, 20). Each of the nine artists was assigned a room within the gallery in which to create a site-specific installation using common materials. Artists employed a variety of common materials, such as: colored string, rubber tires, glass marbles, and index cards. The nine artists featured in this exhibition include: Jennifer Angus, Chakaia Booker, Gabriel Dawe, Tara Donovan, Patrick Dougherty, John Grade, Maya Lin, and Leo Villareal.

Of Wonder (2015), Elizabeth Blair (2015) states, “The natural world is where most of these artists found their wonders," and this certainly holds true for Tara Donovan (American, 1960) (9). Process for Donovan often involves accretion through repetition of a single object or material, a process shared by works by artists like Maya Lin, Jason Rogenes, and Tom Friedman (American, 1965).Donovan lets the original form of her manufactured materials dictate the unified form, which culminates as the final piece. For her, the materials act as organic matter, which she can shape and cultivate but not fully control, the final form is not predestined, but emerges through the process (The Right Stuff: Tara Donovan is the Ultimate Material Girl, 2011). This type of accretion relies heavily on listening, letting go, and giving in to the process; 
like a discovery. For her piece, Untitled (Figure 2) in Wonder (2015), Donovan stacks hundreds of thousands of index cards to form tall white, almost stalagmite looking, ant hills. On her laborious creations, Donovan discusses the cognitive freedom and enjoyment through the extremely repetitive process and the feeling of reward after the pieces' completion (The Right Stuff: Tara Donovan is the Ultimate Material Girl, 2011).

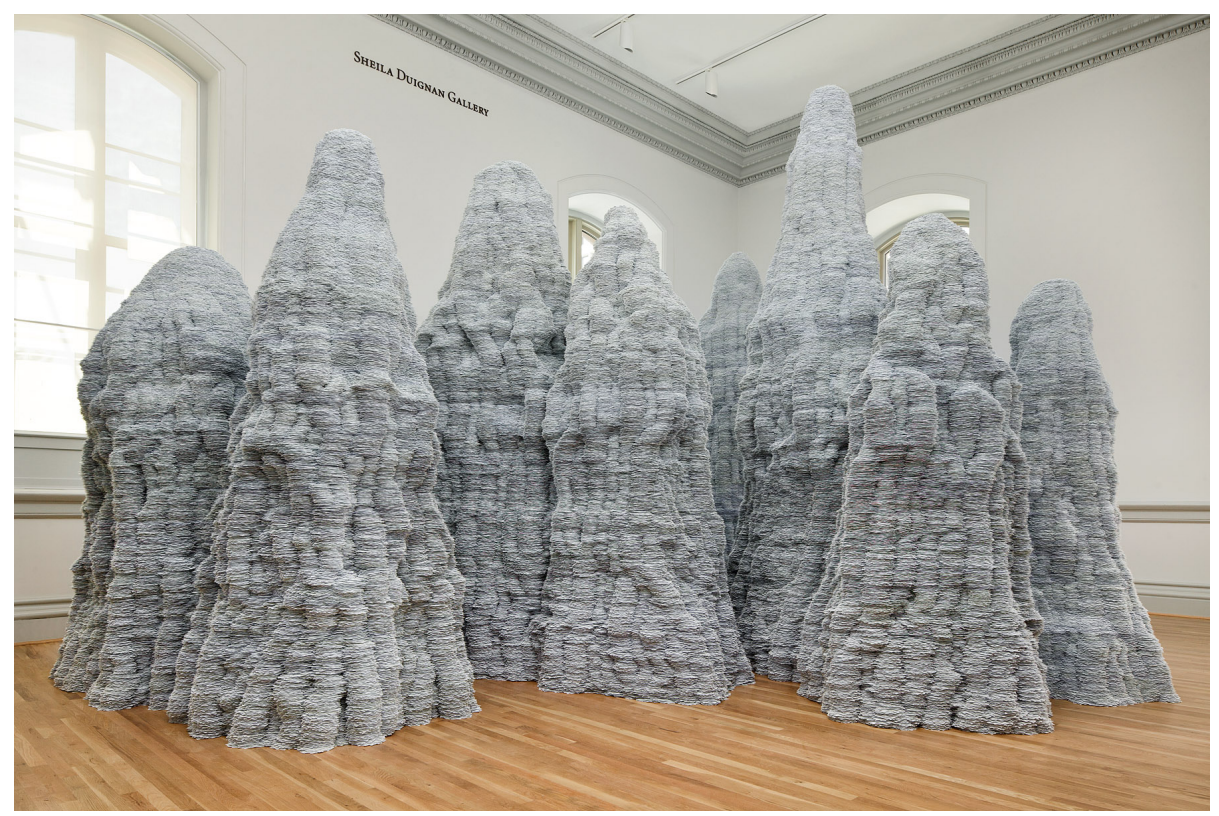

Figure 2. Untitled, by Tara Donovan, 2014, stacked index cards. Retrieved from http://americanart.si.edu/exhibitions/online/wonder/donovan.cfm. Copyright 2014 by Tara Donovan, photo by Ron Blunt.

Tom Friedman also creates startling artworks, which are more often than not, the culmination of a tedious, repetitive process. Like Donovan, "he's allowed his materials to become a self-reflexive (a comment on themselves) but also provided a way to release them from materiality and to become - dangerous term - 'symbolic', operating in the sculpture in ways similar to how DNA or atoms operate in someone considered intimate, known" (Cooper, Hainley, \& Searle, 2003, p. 80). This is evident in his untitled 'starburst' piece which is meticulously crafted from thousands of toothpicks (Figure 3). While he employs both additive and reductive processes his slow contemplative deconstructions of everyday common materials 
are most interesting. For example, Pillow Stuffing (1991) consists of simply "stuffing from a pillow... separated strand by strand into a pile on the floor" (Cooper et al, 2003, p. 18). In this piece, and others from the start of the ' 90 s, Friedman was focused on the experiences and expectations of the viewer. Using innocence as a pivoting point, Friedman likens his process to the revealing of a joke and how it has the power to transform the audiences' perception (Cooper et al, 2003). Viewers gazing upon his Pillow Stuffing likely assume it was simply pulled in one piece like a clump, however, the pile is undeniably delicate and does not resemble a hastily assembled mass. After reading the description Friedman hopes viewers will be startled by the process employed to create the pile, thus causing viewers to consider the process and shift their perception (Cooper et al, 2003).

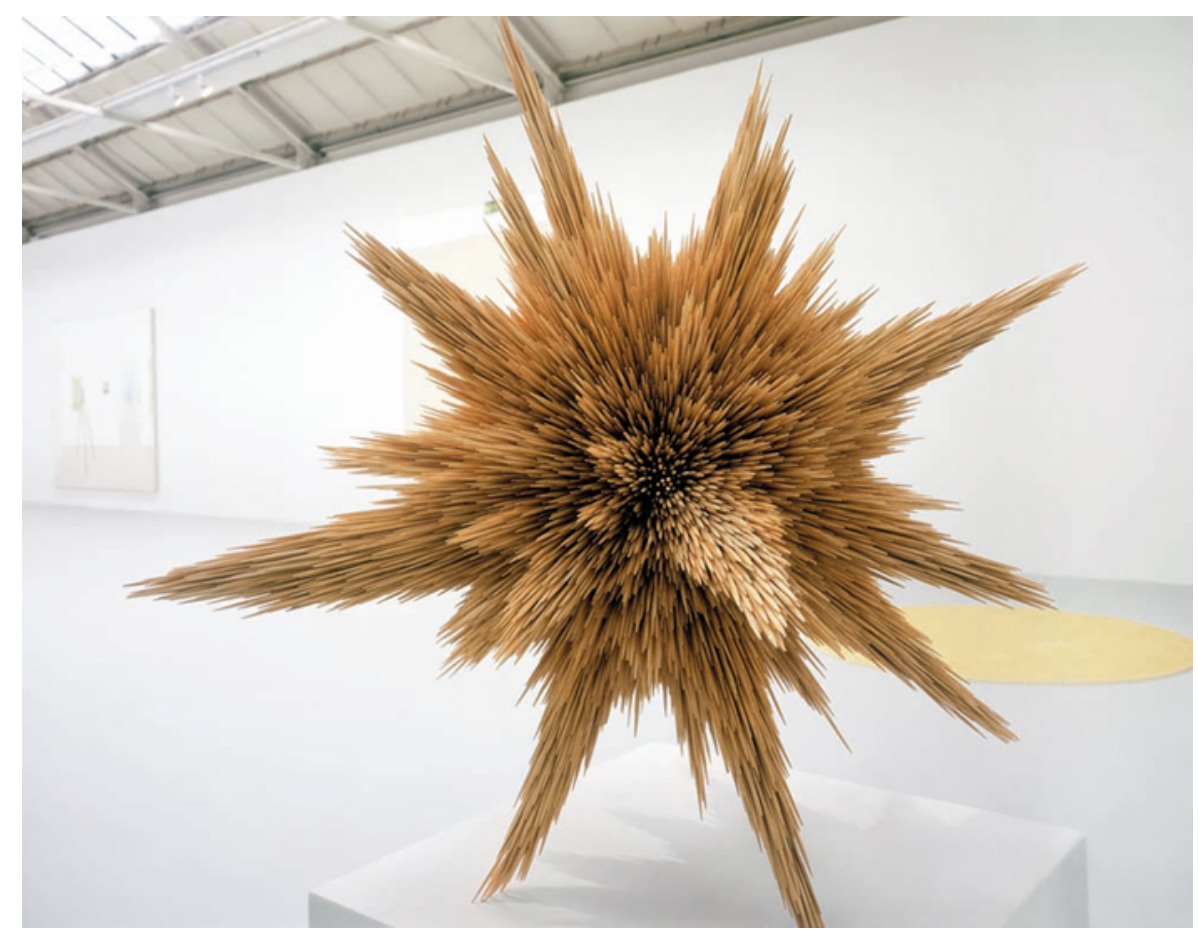

Figure 3. Untitled, by Tom Friedmna, 1995, toothpick starburst. Retrieved from http://www.saatchigallery.com/aipe/tom_friedman.htm. 
Artists, such as: Doh-Ho Suh, Cat Chow, Tom Sachs, and Tony Cragg utilize single objects or materials in much the same way - except their plan is predetermined and often their final form is recognizable and easily labeled. It is worth noting that while Donovan and Friedman's pieces (at least those mentioned specifically within this chapter) resemble organic shapes or forms, which the viewer can reference, the pieces remain open to the interpretation of the viewer through their 'untitled' titles.

To contrast pure accretion, some artists' processes are more reductive. French artist Régis Mayot (1970) studied dissection to create negative structural cutouts of thrown out plastic containers. He elaborates on his concept and the significance of plastic as a material within our culture in saying, "it is the preferred material of industry; saving weight, time, material, energy... and paradoxically, it is the most neglected, the most negatively viewed by the public" (Holt, 2008, p. 53). Though Mayot's work relies more on reduction or negatives he engages in additive processes through collecting and gathering containers, which serves as an example of the overlapping of varying artistic processes. Collecting or gathering materials is a process in it of itself, and it is worth noting that Mayot actively collects his materials. His collection process involves scavenging for discarded items in dumpsters rather than purchasing, as Donovan surely did to obtain her thousands upon thousands of index cards. In Mines (2008) Mayot begins with a reductive process by deconstructing plastic containers (Figure 4). He starts by cutting them into a variety of organic shapes before reconstructing them into a single, hollow plastic form. Like much of Tara Donovan's work, Mines (2008) takes an organic form and works from part to whole. 


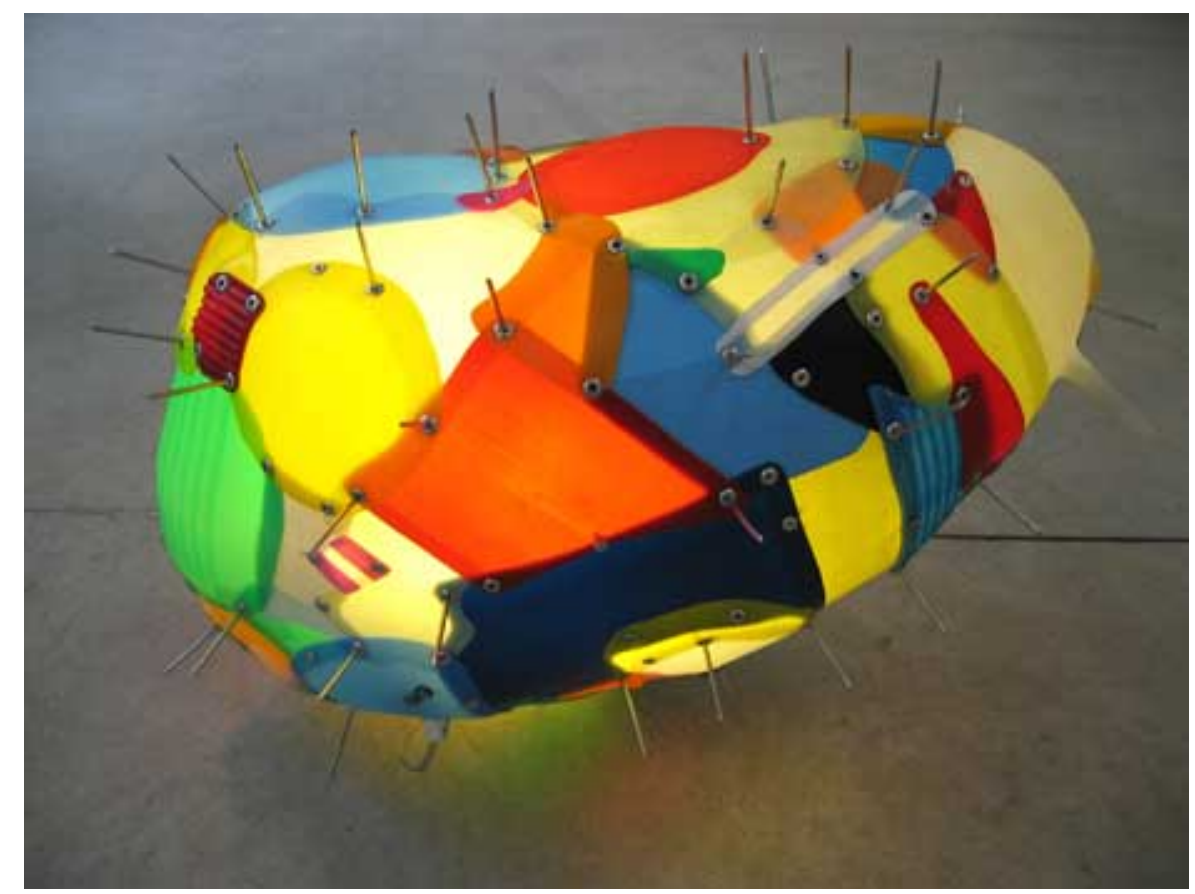

Figure 4. Mines, by Régis Mayot, 2008, plastic patches recomposed into a form. Retrieved from http://museumofcontemporarycraft.org/manufractured/artists/mayot.html.

Chakaia Booker (American, 1953) is another artist who both dissects and combines pieces of material; tires in her case (Figure 5). Anonymous Donor (2015), which was also included in the Renwick's Wonder (2015) exhibition, is composed of old dissected tire scraps which have been reconstructed into a few rows of waving, windowed partitions reaching ten feet high (Figure 5). Booker engages the viewers body, much like Donovan's neighboring index card mounds, allowing the viewer to be affected by space, feelings, and senses.

Booker is just one of many contemporary artists who employ common materials to engage the viewers' senses and inform their perception. "The first thing you notice is the smell. It's a bit industrial, but also, maybe a tiny bit pleasant" (Ault, 2015). The intense smell of rubber works to attract and overwhelm viewers. Ault (2015), a viewer and journalist, associates the smell with a factory and likens the scent to the physical properties of a vast warehouse by stating, 
"it is a bit dark and threatening." The rubber odor permeates the room and "engulfs" the audience much like the physical waving walls may seem to weave around you (Ault, 2015).

Ultimately, Booker wants the audience to decide the work's meaning by interpreting their physical and cognitive reaction to the piece. The viewers' awareness of their own presence, and unity with the environment, through affection and the senses is critical toward understanding her work, she states, "my intention is to translate materials into imagery that will stimulate people to consider themselves as part of their environment, as one piece of a larger whole" (cited in Ault, 2015).

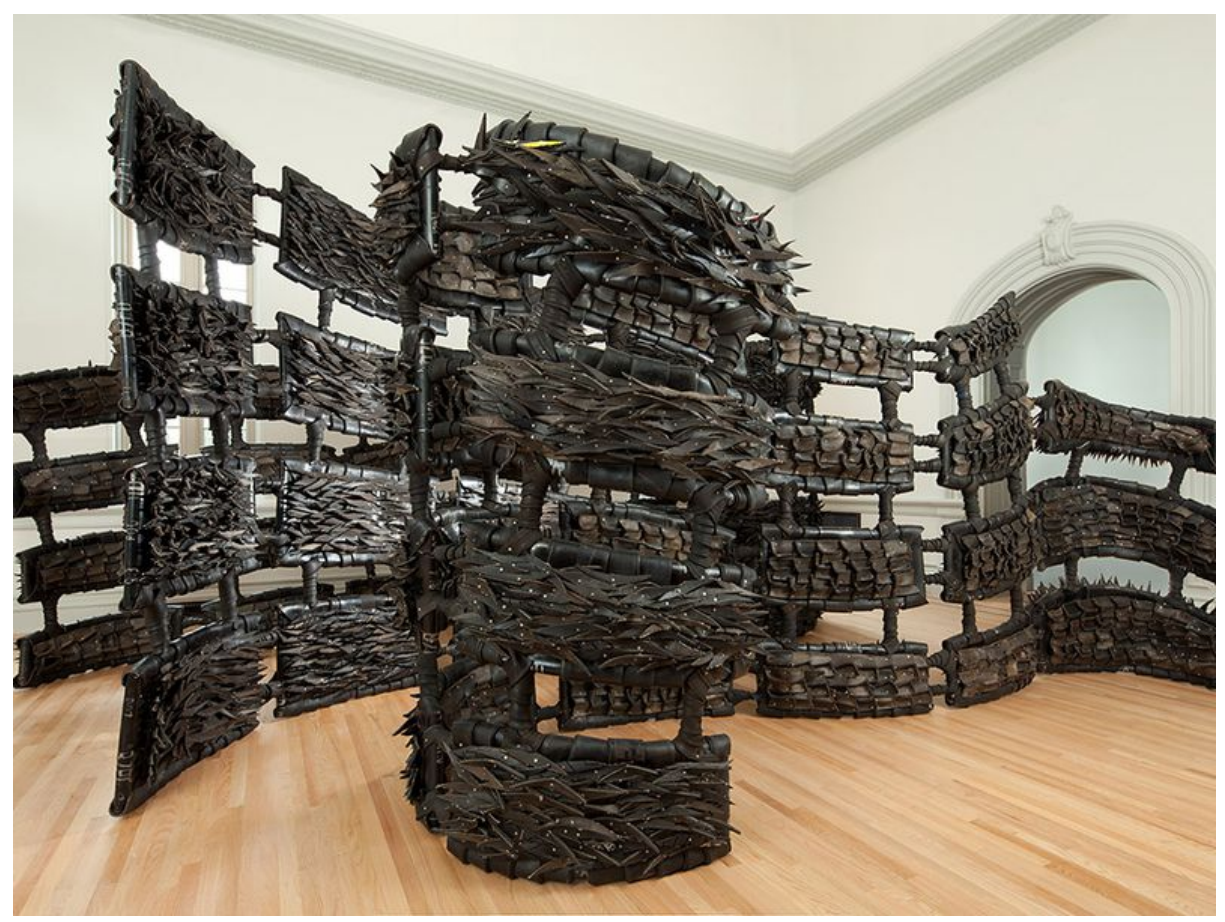

Figure 5. Anonymous Donor, by Chakaia Booker, 2015, dissected rubber tires reconstructed. Retrieved from http://www.smithsonianmag.com/smithsonian-institution/artist-chakaia-booker-gives-tires-powerful-retread-180957362/. Copyright by Renwick Gallery/SAAM. Copyright by Ron Blunt.

Liza Lou (American, 1969) considers sight and touch major facets of her works' perception, as well as its process (Hodara, 2016). In her 2015 installation titled Color Field 
(Figure 6), which showed at the Neuberger Museum of Art in New York, Lou asks viewers to remove their glasses and allow a less than perfect vision to inform the eyes (Hodara, 2016). The vibrant floor installation resembles a field or sea of which Lou refers to as "blades of glass" (Hodara, 2016). Each blade consists of a single colored wire topped with a cylindrical glass bead; her material of choice for decades. Approximately one hundred wire/glass blades are then stuck upright in a grid-like fashion onto a colored tile measuring approximately one square foot. The tiles are then joined on the floor of the gallery creating the 'field'. She appreciates the effect touch has on the work, as the human oils and individual atmospheres become embedded in the pieces (Hodara, 2016). Lou states, "the wood smoke from their cooking, their sweat, the oil from their fingers...it's because of the nature of the human hand" (as cited in Hodara, 2016).

In addition to her awareness of the senses, Lou highlights her reliance on collaborative process in the production of Color Field (2015). The process requires Lou to enlist volunteers within the community, as well as overseas Zulu beadworkers to complete the piece. On the collaborative process Lou states, "To work with other people...to embrace lots of people and to find out what happens when you are put with a lot of people together and how do you make a work of art then, and for me that is part of the process" (Museum of Contemporary Art San Diego, 2013). Her collaborative process gives her gratification by allowing her to converse intimately, tell stories, and share unique narratives with community members volunteering in her studio. "I love that the stories and the lives and the hands are embedded in the work...you can't take that away from the work, it's in the work... when we're holding the material I often think of the women that I work with their hands, their lives, their stories" (Museum of Contemporary Art San Diego, 2013). 
Though human touch and collaboration are important facets of her process, Lou ultimately stresses valuing as an artistic aim. She, states, “we don't value the ground on which we walk...I think my process is about saying, "Look! Look at how things can be made" (Museum of Contemporary Art San Diego, 2013).

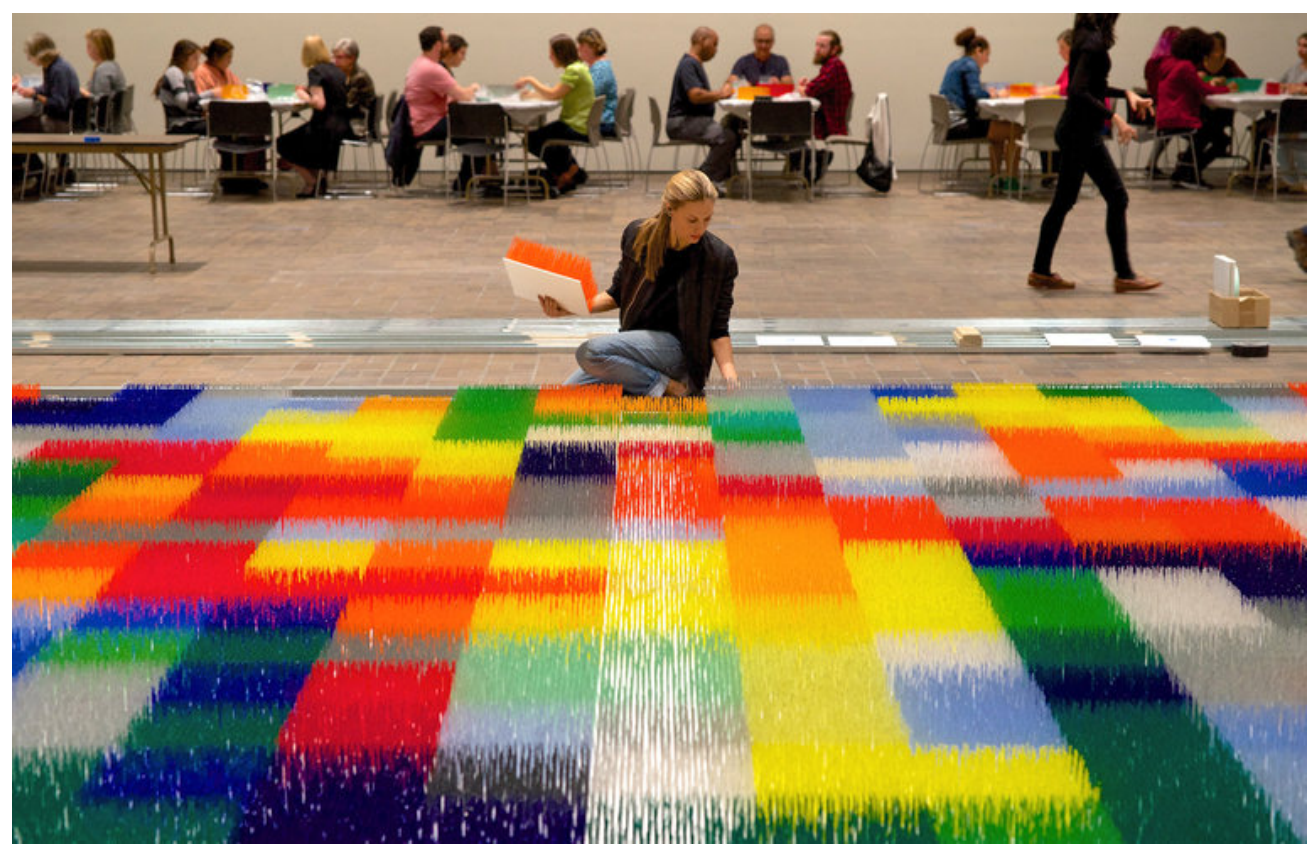

Figure 6. Color Field, by Liza Lou, 2015, tiles of blades made from wire and glass beads. Retrieved from https://www.nytimes.com/2016/01/03/nyregions/liza-lous-handmade-sea-of-sparkling-glass.html?_r=0. Photo by Lynda Curtis .

\subsection{Current Discourse on Contemporary Art in Art Education}

The implementation of a $21^{\text {st }}$ century curriculum which exposes students to contemporary art, artists, and processes is a frequently discussed topic within art education today. Art educators recognize the importance and role of art history, but they also understand that relevant curricular content is important, as well. In art education, the inclusion of contemporary art, artists, and process is both socially and culturally relevant to $21^{\text {st }}$ century learners, as it is a product of their 
place and time. However, the inclusion of contemporary art into the K-12 curricula does not come without challenges.

\section{Importance of Exposing Students to Contemporary Art}

Research within the field of art education advocates for the inclusion of relevant and contemporary approaches to art and making within the K-12 public school curricula (Duncum, 2012; Gude, 2004; Gude, 2010; Leake, 2014; Smith, 2011; Thulson, 2013). Currently the NAEP Arts Assessment (2016) reflects a deficit in middle school students' critical thinking, access to diverse materials, and museum/gallery visits. Though this is generally true, many art educators are the exception and are actively implementing changes toward progression.

One way of exposing students to contemporary art is to take students on a field trip to a museum or gallery. Published studies in art education highlight the benefits of museum visits/field trips toward student learning (Adams, Foutz, Luke, \& Stein, 2007; Bowen, Greene, \& Kisida, 2014; Greene, Kisida, \& Bowen, 2013; Witmer, Luke, \& Adams, 2000). Exposing students to art through museum field trips, whether single or multi-visit, shows marked improvement on students' critical thinking, historical empathy, tolerance, and interest in the arts (Adams et al., 2007; Bowen et al., 2014; Greene et al., 2013; Witmer et al., 2000). Unfortunately, the National Assessment of Educational Progress (NAEP Arts Assessment Report, 2016) reports that only 14 percent of eighth graders went on school organized field trips to museums/galleries. Given the current undervaluing and underfunding of the arts, student exposure to art through museum field trips is not a sustainable solution for many public art education programs, so art educators must find other means of exposing students to contemporary art. 
There are several approaches toward exposing students to contemporary art, artists, and processes which educators employ within the classroom. Some art educators incorporate emerging technologies, such as video art, as an alternative form of art. While the incorporation of emerging technology as a form of art-making is certainly valid and important it is not inclusive or exhaustive, as there are other contemporary forms of art-making when confronting contemporary genres. Additionally, the general conceptual complexity often accompanying of video art or performative pieces may be better suited for high school aged students, as Ridge (2015) implemented with her students. Furthermore, access to digital equipment necessary for video art may be limited or difficult to obtain due to hardware/software cost, teacher's technical knowledge, or limited volume of equipment. Though the integration of digital media as an art form is one method of combating the problem, it is only partial.

Research within art education demonstrates how contemporary genres are yet another approach which some art educators employ within their own classroom. These art educators focus their curricula on progressive critical thinking and concepts by incorporating contemporary genres, such as social issues or change, rather than contemporary materials or form (Gude, 2004; Leake, 2014; Ridge, 2015; Thulson, 2013). Contemporary genres are an important facet of much contemporary art; however, contemporary genres can be addressed easily through traditional/canonical forms of art-making.

Each approach exposes students to contemporary art within the classroom, whether through contemporary processes/form or contemporary genres, is a step toward a more progressive and substantive $21^{\text {st }}$ century art education. However, regulating contemporary art approaches to digital forms of integration is exclusive, and may prove to be costly. Contemporary genres offer a broad approach, but educators must be careful not to facilitate 
solely traditional processes of art-making. Attention to the inclusion of contemporary art-making processes outside of the canon or merely digital should be addressed.

\section{Impediments to Introducing Contemporary Art into the Curricula}

There is a contradiction between learning opportunities currently provided within the art classroom, specifically in relation to form and medium, and contemporary artistic behavior and practice (Gude, 2004; Thompson, 2015; Thulson, 2013). While many art educators continue to focus on art-making within the canon of painting and drawing (NAEP, 2008; Pavlou, 2009), opportunities to engage in contemporary art-making processes are often neglected as teachers take ownership through traditional predesigned projects within the art classroom. Many art educators believe in the importance of choice and student agency; however, choice is typically limited to that of subject or content, rather than form or material, within a highly structured or nearly closed-curriculum. Thuslon (2013) highlights a problematic perspective shared by some art educators who believe that "young students must learn the "basics" — self-expression and design principles — before they can fully participate in contemporary curriculum” (p. 16). McElhany (2017) counters this obstructive viewpoint, by stating, "with an overwhelming focus on comprehension and application of formal qualities and technical strategies, many students demonstrate difficulty recognizing and explaining conceptual meaning within their artworks. Furthermore, many visual arts curricula focus on replicating subjects or characteristics of master artists and/or exotic cultures rather than allowing students to explore their own identity and culture through meaningfully chosen media (McElhany, 2017). 
The ambiguous nature of contemporary art unsettles educators and results in a lack of explorative processes of art-making (Joo, 2011; Villeneuve, 2008). Pat Villeneuve and Mary Erickson (2008) address the issue of perceiving and appreciating contemporary art:

Many people in the United States are not equipped to deal with it. In our work with preservice and in-service art teachers, general education students, children, docents, and the general public, we find that young and old alike seem more comfortable with art that is representational and attractive. Both groups can be stymied by conceptual, performance, or installation art or the unconventional materials sometimes used by contemporary artists. (p. 92)

Thus, many art educators avoid the inclusion of contemporary art, artists, art-making processes, and materials within their curricula due to a lack of self-assessed comprehension and therefore confidence (Joo, 2011). I say self-assessed because educators often feel as if they should "know it all" which contradicts a constructivist attitude, as well as the inherent nature of contemporary art. Although Anne Thulson, a former elementary art educator and now assistant professor of art education, uniquely contradicts other educators doubts by boldly advocating for contemporary art practice starting as young as elementary school. Thulson (2013) argues, "Tangible products can be made within a conceptual, contemporary framework. Parents and administrators are capable of understanding and supporting contemporary approaches. Modernist instruction...is a counterproductive foundation for future postmodern curriculum” (p. 16).

Museum and gallery field trips could be one solution to the problem of educators' lack of confidence in incorporating contemporary art into their curriculum, as art specialists could facilitate student learning in a museum context. Unfortunately, due to a lack of funding students are less and less likely to have access to museums and galleries as a regular part of their middle level arts education, so this an unlikely sustainable solution (NAEP, 2016). Thus, students may only 'experience' three-dimensional contemporary art through digital documentation or online 
platforms, which does not allow for perception of space, time, and the sensorium as the artists' intended.

\section{Summary}

Today's artists express and represent ideas and meaning through a variety of media outside of the traditional canon, such as: sound, performance, events, light, video and digital art, and everyday objects/materials; the focus of the artists discussed in chapter three. To ignore this reality in the art education classroom is a disservice to young learners (Gude, 2004).

Furthermore, evading the facilitation of opportunities for contemporary artmaking with nontraditional materials does little to encourage students' comprehension of contemporary art, the art of their time about their culture. Maria Leake (2014) explains, "Exploring contemporary art inside and outside of the classroom is an effective approach to connect learning about realworld issues and concerns with our own personal experiences, thus reinforcing how art is a reflection on life" (p. 25). Middle level arts educators can provide opportunities for students to experience and appreciate contemporary artists and process inexpensively and feasibly within the classroom through common materials, however, there are challenges.

\subsection{Conclusion}

Beginning with a brief overview of the birth of contemporary art, this chapter: reviewed a selection of contemporary artists and their art-making processes; highlighted the benefits of exposing students to contemporary art; and discussed issues and limitations within current art education regarding the inclusion of contemporary art, whether of substantive information or opportunities for authentic practice in the form of materials. Many contemporary artists represent 
ideas through common materials; giving them new life and function. This review of contemporary sculptors: Donovan, Friedman, Mayot, Booker, and Lou provides a real-life, yet professional context for which to connect and align the nine artistic behaviors when presented in the following chapter. These artists' works engage viewers with space, time, and the complete sensorium. Furthermore, their processes often include collaborative and collective facets, which are often significant in many large-scale contemporary art installations or exhibitions.

Museums and galleries have broadened their curatorial scope allowing for exhibitions which may have previously been deemed low-art; involving common materials or craft. Contemporary art galleries and museums often strive to awe visitors through art which transforms how people perceive everyday life, the Renwick's Wonder was such an exhibit (Blair, 2015). The curator for Wonder, Nicholas Bell, aimed "to remind the viewer why going to a museum is more rewarding than seeing something on paper or on-line" (Ault, 2015). Unfortunately, as the arts are more and more undervalued and underfunded, opportunities for students to experience this transformative artwork in person is unlikely. Thus, students may only experience three-dimensional contemporary art through digital documentation or online platforms, which does not allow for the student to authentically experience the artwork through the perception of space, time, and the whole sensorium, as the artists intended.

\section{CHAPTER FOUR}




\section{Methodology}

\subsection{Introduction}

The purpose of this study was to examine the potential of material culture art lessons towards cultivating artistic behaviors and enriching middle-level students' perceptive and conceptual understanding in a contemporary educational context. This chapter will discuss the research methodology and design of the proposed research, which aims to unveil how art lessons utilizing common materials (i.e. everyday objects and materials) affect students' comprehension of contemporary art/processes, engagement with artistic behaviors, as well as appreciation for common materials within the world around them.

\subsection{Methods}

The methodology for this study is a qualitative single case study consisting of lesson plans developed and implemented as a field test towards analyzing the role that nontraditional art-making materials and objects can serve in art education in-regard-to student learning. A qualitative research methodology was adopted for this study because it is an approach which allows the researcher to investigate the topic holistically through multiple perspectives, and allows for the "reflexivity of the researcher" (Flick, 2009, p. 14). One important facet of qualitative research, which differs from quantitative, is that the "researcher's reflections on their actions and observations in the field, their impressions, irritations, feelings, and so on, become data...forming part of the interpretation, and are documented in research diaries" (2009, p. 16). Additionally, analysis of qualitative research is descriptive, high-inference or interpretive, and it illuminates depth rather than breadth. Furthermore, a single case study approach was selected allowing me to create and control the lessons through the role of a participant observer, which I 
will discuss further later in this section. A case study allows for an in-depth examination and a reflexive and interpretive description of a specific phenomenon, in this case a class of middle school art students' experiences investigating and creating collaborative contemporary art.

After deciding middle school would be the focus for this project, I observed two exemplary middle school art educators whose practices informed my proposal. The first art educator, outside of Chicago, Illinois, was chosen based on a recently published study which illuminated strategies for contemporary art inquiry. The second middle school art educator, outside of Richmond, Virginia, was chosen because of her choice-based pedagogical approach known as Teaching for Artistic Behavior (TAB). Both teachers demonstrated pedagogical and instructional strategies, which informed my approach to this study and the construction of my non-traditional art making lesson plans.

I collected qualitative data before, during, and after implementation of the lessons in the form of: observations and field notes; a reflective research journal; student journals/assignments; pre-and post-questionnaires; and photo documentation of the artwork throughout the making process and after completion.

My role as both the researcher, by collecting and analyzing data, and the teacher, by creating and implementing lessons, is defined as a participant observer. Participant observation is a "field strategy that simultaneously combines document analysis, interviewing respondents and informants, direct participation and observation, and introspection" (Denzin, 1998, p. 157-158). Observations may be quantitative by counting and tallying the number of times a specific behavior is acted out, however, for this study a qualitative approach to observation was employed toward recording rich holistic descriptions through observational field notes. Observational field notes are more than a mere record of events factually as they happen, but 
rather they illuminate both the dramatic, or the mundane as they relate to the topic. Additionally, by being a participant observer I could record observations, which were influenced by my participation rather than as a non-interacting observer. This position, as a participant observer, allowed me to observe more deeply and meaningfully through face-to-face engagement with participants, focusing the activity to further elaborate on particularly interesting interactions or phenomena.

Students were given in-class writing prompts as formative data collection, which surveyed students' knowledge of contemporary art, artistic behaviors, and material culture. Additionally, more formal questionnaires were given to students after the study as a form of summative data collection. For example, an exit questionnaire was given to students at the culmination of the project.

Triangulation refers to the utilization of multiple research methods or data within the design of the research, and it is critical toward insuring the validity of the research (Denzin, 1998). For this study, I collected data from the participants, myself as the participant-researcher, as well as photo documents. Collecting data from multiple sources, rather than one, enriches the data with multiple perspectives and decreases researcher bias. In addition to collecting data from multiple sources, I utilized a variety of research methods throughout the data collection process, such as: observational field notes; a reflective research journal; student journals/assignments; pre-and post-questionnaires; as well as artwork analysis.

\subsection{Site}


Research was conducted at a public middle school in Monongalia County, located in Morgantown, West Virginia. The middle school, which originally served as a high school until 2008, was built in 1933. The student body consisted of 518 students in grades sixth, seventh, and eighth. The middle school consisted primarily of students identifying as Caucasian (represented by approximately $91.5 \%$ of the student body), with $3.1 \%$ Two Races, $2.3 \%$ Black, $1.5 \%$ Hispanic, and 1.5\% Asian. Although the state of West Virginia as a state reflects test scores below the national average, Site A students' test scores in Math and ELA are slightly above the national average. Additionally, the school is above average socioeconomically compared to the city of Morgantown, as it represents a lower percentage $(18.3 \%)$ of students eligible for free/reduced lunch comparative to the city of Morgantown, which represents $39 \%$ of students eligible for free/reduced lunch.

The art classroom, which facilitated the research activities, was an addition to the original building completed in 1994. The classroom consists of: nine large rectangular tables for students to work; two tables abutted together for demonstrations and supplies in proximity to the teacher's desk; four windows along the length of a long wall; three semi-functioning desktop computers; white cinder block walls; linoleum tile flooring; and an elbow shaped counter space with two sinks and white cabinetry above. Beyond the classroom there is a large storage room which houses additional sinks, an oven, kiln, drying racks, and cabinets filled with bulk materials/supplies.

Exhibition space within the classroom was limited to a bulletin board and above cabinetry space about two feet from the drop-down tile ceiling, which was currently being used to display works from previous years. Space for displaying artwork within the school commons 
was limited to two $2 \times 4 \times 4$ foot inset display cases with sliding glass doors immediately outside of the classroom, wall space outside of the office for two-dimensional works, and the library.

\subsection{Participants}

I chose to focus on middle school for my study for several reasons. First, middle school can be either the first or last time a student receives art education, and because of this, age proves to be a pivotal period within many students' educational landscape. Thus, attention should be given to learning through inquiry based research. How can we make the most of this time? What can we do as educators to enrich learning? How do middle schoolers perceive the arts? Second, middle school, unlike elementary school, is a place where play is not generally encouraged, where recess has often been cut, and in which order and discipline are stressed. Lastly, my experience as a substitute teacher uncovered a deep appreciation for middle school students and a drive to ignite their human potential.

Participants for the study were a single class of students selected from my assigned sixweek middle school placement as a student teacher. The cooperating art educator, which I worked alongside, helped inform which class/group/body of students was chosen for this study. The class selected for the study was the Art Honors class, which consisted of 29 students, of whom 27 participated in this study. The sample size of 27 students consisted of: 18 seventh grade students and 9 eighth grade students; 7 males and 20 females; 23 students identified as Caucasian and 4 students as Other.

Permission was received through the cooperating teacher, as well as the administration prior to beginning the study. Both parental/guardian consent and student assent were required recruitment procedures due to the students being minors. First, parents/guardians of students 
were asked for consent to participate through a cover letter and formal consent form. Second, students, only those whose parents/guardians provided consent through the proper documents, were given further explanation of the proposed research and provided adequate time to ask questions before offering voluntary assent by signing the appropriate forms. Any student who did not consent him/herself and/or whose parent/guardian did not allow consent was not mentioned specifically within this thesis. Those who did consent were referred to by an alias. Data was collected in the form of observation, document review, and image review. No names or identifying photos were included in this thesis.

\subsection{Data}

Qualitative data was collected before, during, after the study. Data came from varying sources and was collected in different forms. The data methods used are as follows:

\section{Observations \& Field Notes}

Observation is not considered a form of data collection until it is written, thus all observations were recorded as field notes. All observations were recorded as field notes by hand within a field notebook. Student observations allowed me to capture the minuet idiosyncrasies, attitudes, dispositions, and reactions of students at work. This form of data collection allowed me to access student thoughts and perspectives, which are often challenging to capture in written form when thoughts are less impulsive and more guarded. Ultimately, my observations of student activities provided the richest data.

\section{Reflective Research Journal}


In addition to observational field notes, I kept a digital research journal which is a form of data collection often used in qualitative research. The research journal served to capture my own feelings, thoughts, and reflections as the participant observer, as I was not just a bystander. At the end of each day, I sat down directly after class and promptly typed my reflections into my computer. Immediately recording my thoughts kept them rich and safe from depletion.

\section{Student Journals/Assignments}

Students were given journals to take notes, brainstorm, and sketch whenever necessary during class. Journal prompts were sometimes assigned, especially when I wanted to capture all students' thoughts on a particular point readily. Sometimes students wrote individually within their journals, while other times one person within the group wrote on behalf of everyone during group brainstorming sessions. The journals provided a way to make student thinking visible.

\section{Questionnaires}

Questionnaires were given to students to complete before starting and after completing the project. Questionnaires were used to access students' understanding of contemporary art, materials used to create art, as well as their engagement in the collaborative art-making process. Additionally, the post-questionnaire gauged students' opinions and attitudes towards common materials.

\section{Artwork}

Artwork and art-making in it of itself served as my data. Throughout the progression of the project I captured images of students at work. Problem solving discoveries and methods were 
documented through photography. Capturing student activities through photography allowed me to review the imagery later for further analysis, which may have been initially overlooked.

\subsection{Limitations}

Research, as with all facets of lived experiences, invariably comes with a series of assumptions and limitations, regardless of the expertise of the researcher or the quality of the design. Recognizing and addressing assumptions and limitations within a research project is the diligence of the researcher (Flick, 2009). I identified two limitations of this study, those being:

1. Limited access to the classroom:

My position as a graduate student participating in student teaching placed me under the direction of my cooperating teacher and limited my access to the classroom. Additionally, my role as a preservice graduate student and student teacher, rather than as teacher student (or graduate student who is already certified and actively employed as an arts educator), reflected limitations in-regard-to experience and expertise. Although I have completed the required courses to become a certified K-12 art educator, and I have participated in the necessary clinical experiences through student teaching, I am not an experienced educator. My role as a novice art educator is certainly a limitation to the study. The facilitation of collaborative class-wide artmaking and the foresight to recognize arising issues are experiences not commonly had by novice teachers.

2. The space was not my own classroom:

Due to my position as a student teacher working alongside a cooperating teach, the space in which we worked was not my own, but my cooperating teacher's classroom. The project was limited due to borrowed space for both creating and exhibiting works. Space is precious within 
an art classroom, as storage for art supplies and works in progress often combat areas of clean and clear surface space required for creating. In addition to space, it was necessary for the cooperating teacher to be on board with the project, as I was essentially under her direction. I consulted with the cooperating teacher regularly to be open to her suggestions, as well as to make certain I was still meeting her curricular needs. 


\section{CHAPTER FIVE}

\section{Data Analysis}

The purpose of this study was to examine the use of material culture art lessons in cultivating artistic behaviors and enriching middle-level students' perceptive and conceptual understanding in a contemporary educational context. This chapter describes the data resulting from a two-week long collaborative art project utilizing common materials. The study attempts to offer a solution to the problem of student opportunities for access to contemporary art, due to the increasingly underfunded and undervalued arts, by examining an inexpensive way in which to bring contemporary art and processes into the middle school classroom. This chapter is divided into three sections, one for each guiding research question. Additionally, the Research Question 2 will sub-divided to specifically address the nine artistic behaviors.

For Research Question 1, how do material culture lessons promote student understanding of contemporary art in a middle school art class, I used a pre-and post-questionnaire to gauge students' definition of art and understanding of materials used to create art. I recorded observational field-notes on art-making activities and class discussions involving contemporary art analysis. Additionally, student journals/assignments were used to record students' thoughts and opinions on art, as well. All data was entered into a Word document, converted to a table, color coded, and interpreted for analysis.

The scope and collaborative nature of the project provided an opportunity for the students to understand how large works of art and/or installations often require several people working collectively toward a common goal. The students worked collaboratively to create a large wire willow tree, with a focus on process. I predetermined the predominate material — a variety of electrical wires ranging from power cords to Ethernet cables. This was necessary for two 
reasons, 1) I needed to ensure that we could collect the supplies in large quantities, quickly, and inexpensively; and 2) the material needed to be conducive to a collaborative, approximately 30 middle school students, working at tables. Presenting the students with the predominant material meant that form and meaning followed the material. Like many of the contemporary artists mentioned in chapter three, the students were presented with an excess, or discarded material, and left to find a purpose and meaning — to take nothing and make it into something.

When asked if the project helped the students better understand contemporary art, all but two students reported positively. Student 1 simply wrote, "Yes, I know what it is now", as if to say that before the project they had no inkling of what contemporary art meant. Student responses to their understanding of contemporary art addressed both physical engagement and cognition. Student 24 felt the experience of physical engagement was particularly beneficial, she stated, "Yes, because we got hands on during the process which showed us how it is made." Student 8 responded similarly, she wrote, "Yes, because it's one thing to see it and another to make it." Student 11 wrote, "I feel it did help. You had to understand and build an idea before, then you put everything together to make a beautiful piece." Student 11's response highlights the cognitive processes involved in art-making when the artist must infer, interpret, and construct knowledge based on a specific material; whether given or chosen. Furthermore, the student's response reflects an understanding that form, and more importantly meaning, often follow material.

For Research Question 2, how do material culture lessons support artistic behavior among middle school students, I observed classroom activities and the students' creative process, which included both activities of engagement and cognition. Most observations were recorded by pen and paper throughout the class period within a notebook, however, some observations and 
my teacher reflections were also recorded within a Word document at the end of each day. Additionally, I used student journals/assignments, questionnaires, and student artwork review. All data, except photo documentation of artwork, was transcribed into a Word document and converted into a table for analysis. One of the aims of the two-week long material culture art lessons I implemented was to support artistic behaviors. Throughout the lessons students consistently participated in a wide range of artistic behaviors. Using a deductive method of analysis, the nine artistic behaviors: problem finding, problem solving, constructing knowledge, experimenting, working habits, representing, reflecting, connecting, and valuing were utilized to categorical code data. The following paragraphs address these nine behaviors, in alignment with the literature review.

\section{Problem Finding}

Problem finding was most evident when I presented the students with objects to analyze, as well as the common material in which the students would be collectively working with toward creating a three-dimensional art piece. I wanted to warm students up to the idea of problem finding and interpreting meaning with everyday objects by practicing a categorical analysis before addressing the primary material for the project. We discussed what it means to "analyze" and I presented a graphic organizer with subcategories: description, emotion, reference, audience, and theme (Grodoski, 2016). This organizer supported students' investigation of a single common material which I placed on each groups' table.

After the students analyzed a variety of objects, I showed a PowerPoint including contemporary art composed of everyday or common materials. Throughout the PowerPoint I was able to further scaffold student learning by facilitating a class discussion. The class discussion 
allowed students to apply analytical strategies of investigation to more complex imagery (i.e. contemporary art).

Following the analytical exercises provided through the everyday objects and contemporary art, I unveiled the predominate material (various electrical cords and wires). For this project, form followed material and meaning. Like many of the contemporary artists mentioned in my literature review, the students were presented with an excess, or discarded material, and left to find a purpose and meaning — to take nothing and make it something. The identifying question was, “what does wire represent, what can wire mean?”. The students collectively discussed and analyzed the material (Figure 7), by applying the categorical analytical format provided, before visualizing possibilities.

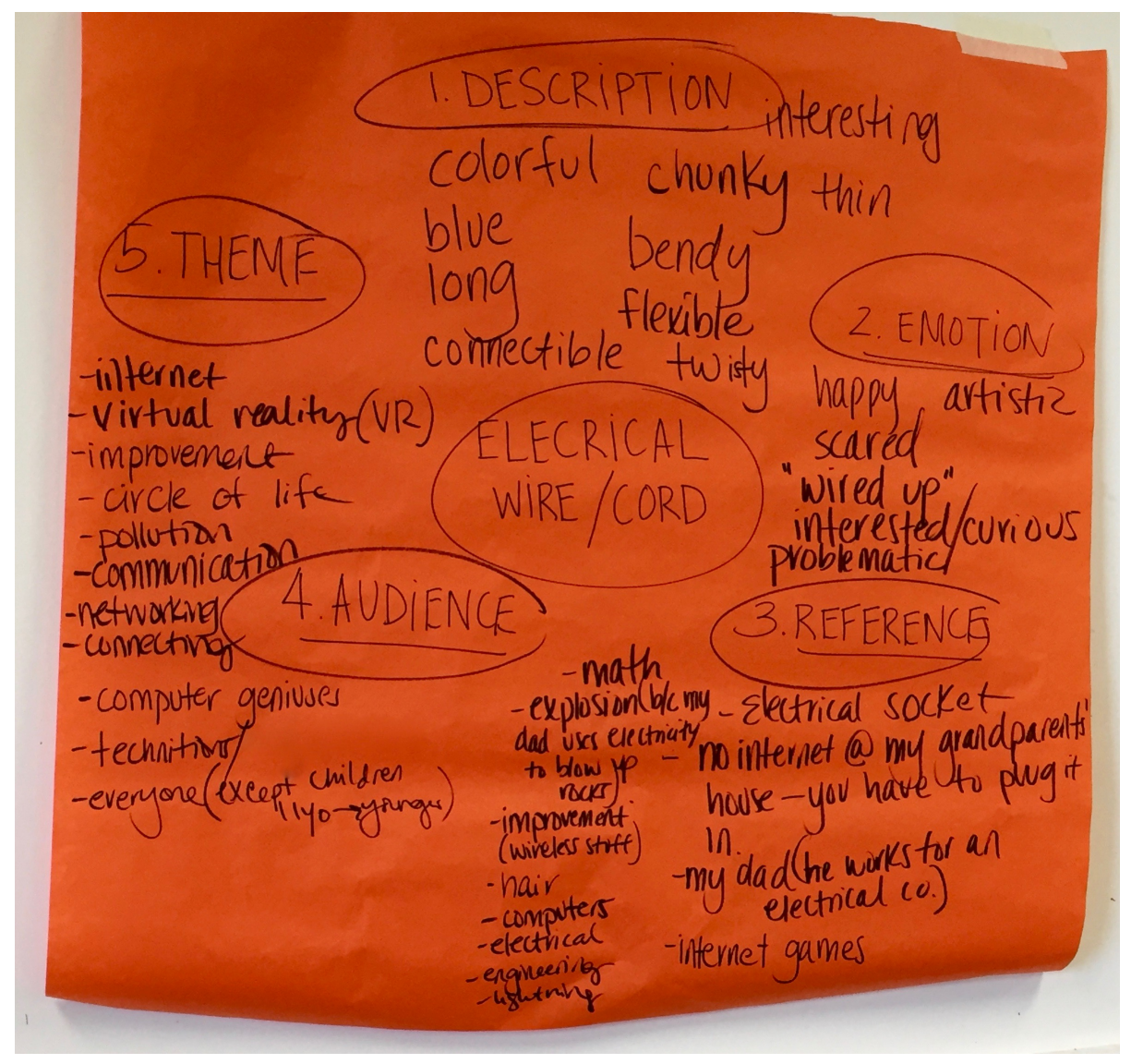

Figure 7. Collective analysis of electrical wire/cord completed through a class discussion, which I recorded on a large piece of roll paper. It remained taped to the wall throughout the two-weeks. 


\section{Problem Solving}

Engagement with a new material provided many opportunities for problem solving. For example, some of the electrical cords, those which had a thick rubber casing and harbored several smaller wires, proved to be challenging to cut and dissect. The students initially struggled to uncase the cord by pulling the casing directly from the group of wires, sometimes using their feet to gain leverage. Student 1 discovered the first solution to more easily and efficiently dissect the cords. The solution was to separate the group of wires into two, some in each hand, and then pull the two groups apart. This method required less strength, as the wires worked to split the casing apart. After sharing this solution with the entire class another student shared a different method they had discovered. Student 18, "I have been just like cutting the cord into parts and then pulling it off." This student was slicing the diameter or the casing every 4-6 inches and then sliding the casing off the end of the grouped wires within.

Another instance of problem solving arouse when attaching the willow vines to the tips of the branches. Student 4 found that the larger rubber casing, which came from extension cords, created a sleeve when empty (Figures 8 and 9). Student 4 discovered that the sleeve allowed one end to wrap rather seamlessly around the tip of the branch, while the other end could be stuffed with 'willow vine'.

Problem solving was exciting for the students. They were proud of their discoveries and new methods and were eager to share with the collective. To this end, the student became the teacher. The examples mentioned are not exhaustive, but rather reflect a few specific ways in which the students engaged in problem solving, from a technical perspective, throughout the artmaking process. 


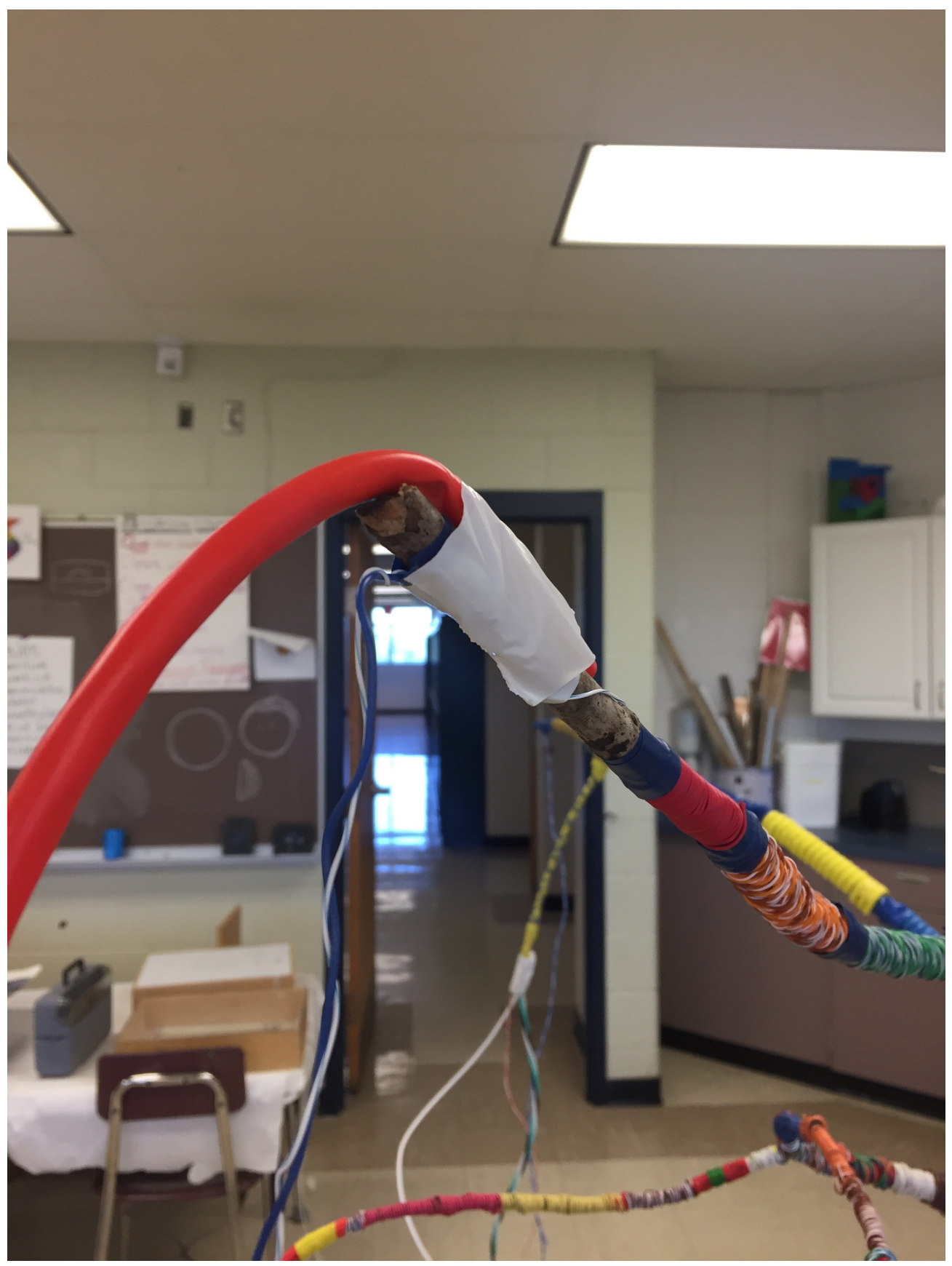

Figure 8. Student's initial method of attaching willow vines to branches, which does not create a smooth transition from branch to 'vine'. 


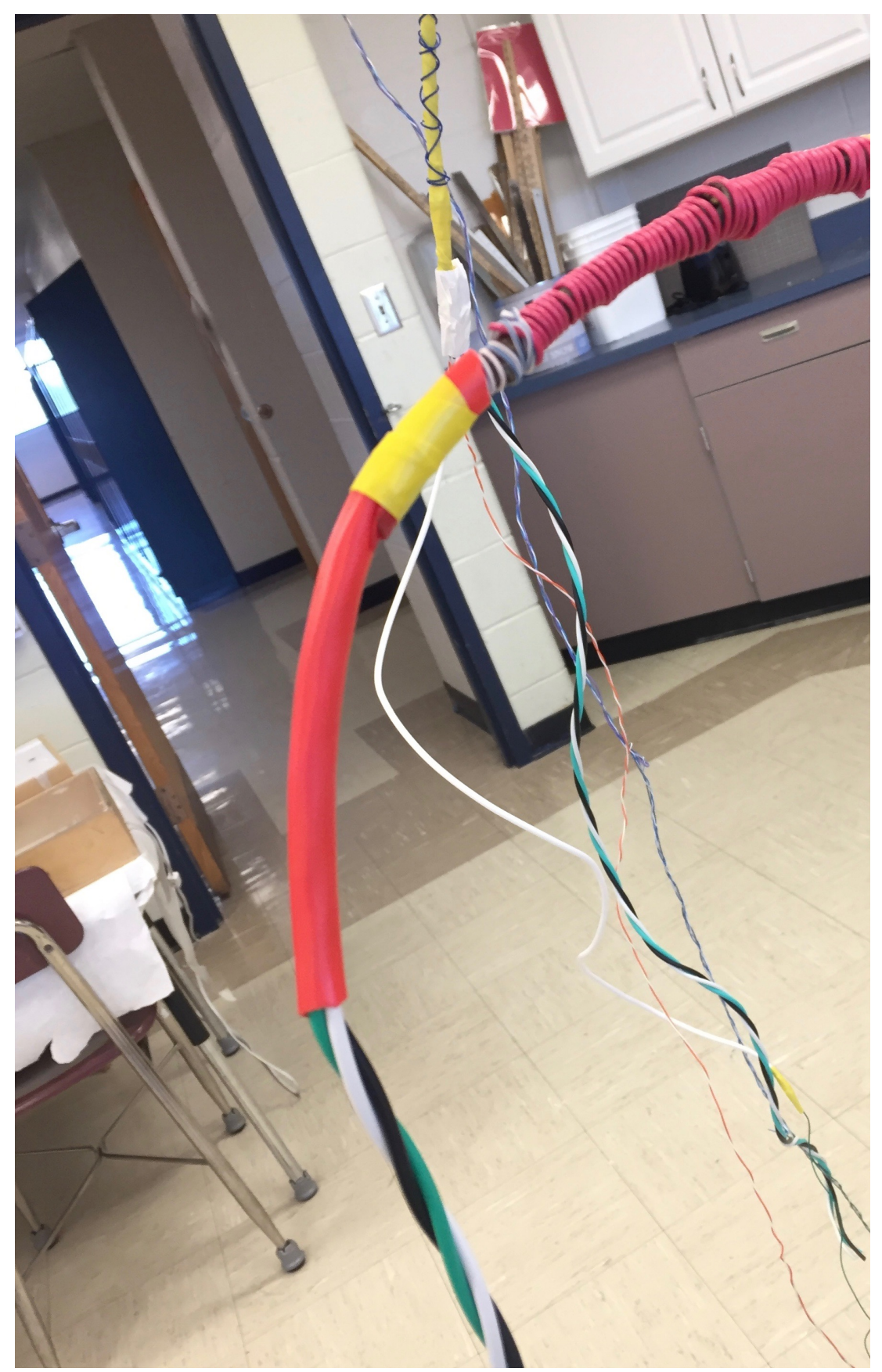

Figure 9. Student's solution to the abrupt connection between vine and branch. Orange extension wire is hallowed out so that it may be wrapped around the tip of the branch. The inner cords (white, black, green) are left to dangle and the orange casing is secured with yellow electrical tape. 


\section{Constructing Knowledge}

Student 20's exclamation of creating a tree during the experimenting phase of the project proved to be a lasting impression, which informed a later episode of constructing knowledge. After analyzing and interpreting the embedded and potential meaning of electrical wire/cord, the students suggested creating a tree, because it too can represent knowledge. During one of our brainstorming sessions Student 4 announced, "I have an idea! How about the tree of knowledge?". We considered this idea collectively through a class discussion in which students presented several different ideas. Ultimately, the students decided that a tree appropriately related to the theme of knowledge, power, and growth represented by data/network/power cords and wires. Taking this idea, the class reflected on what a tree could mean or represent, and they applied the deductive analytical categorical process to then induce meaning. Collectively the students composed a list of concepts a tree may represent, they were: knowledge, growth/life, family/connection, networking, nature/earth/environment.

\section{Experimenting}

Experimentation was a key behavior, and over time, new artistic processes were discovered and employed by several students as a result of material exploration, as mentioned under the sub-section addressing problem solving. Students were given time to explore the material freely, to examine its properties and potential as a medium. This period of play was exciting for the students, as immediately after I unveiled electrical cord/wire as the primary material for the project, Student 7 exclaimed, "Yay! It's not paper." It is important to note at this point that the students were a week deep in two-weeks-worth of standardized testing; computer based. Time allotted to deviate from "school” or computer or paper/pencil based learning 
activities appeared to be much needed and appreciated. This was further proved when I was specifically told by the Technology Integration Specialist (TIS) at the school to avoid technology integration during the standardized testing weeks.

Experimentation played a large role initially, as students played with the raw wire, a process that allowed ideas to emerge. For example, the image/idea of a tree initially surfaced when Student 20 exclaimed, “look I made a tree!”. This epiphany came after he dissected about 8 inches of thick wire, revealing a handful of smaller copper insulated wires, which bent in a mess resembling branches. The idea for a willow tree was later recalled and then solidified after the students recognized the connection between data/electrical cords and trees, as both can be used to communicate the theme of knowledge.

\section{Working Habits}

Several working habits were supported throughout this project, however, I will only address those which were most significant. Planning, collecting, and collaborating emerged as significant working habits throughout the process. Planning was evident through student sketches and discussions on potential problematic situations. Students often discussed or sketched ideas for the project. In addition, we openly discussed the best methods and process, as well as shared solutions to problems. Furthermore, planning proved critical towards navigating the logistics of relocating the tree from the second-floor classroom to the first-floor library, which required attention to at least three doorways. Collectively students accessed the tree, envisioned possibilities, and planned for a certain allowance of branch flexibility - allowing the tree to be moved between the necessary thresholds. 
Collecting materials was also a critical working habit, as the project relied heavily on damaged, unused, or unwanted electrical cables and cords. Students were excited to contribute to the cause, and would proudly show me the haul of cords which they had collected for the project. Collaboration was another critical working habit (Figure 10 and 11). One of the most exciting and energy fueled areas of activity was the tree's trunk, which was situated near the double sinks away from the group tables. Within my field notes I observed students working together in undefined groups, switching back and forth between helping and assisting different people. I wrote:

Hands are becoming as entangled as the wires as students surround the trunk working diligently. Students seem to be working unaware of anyone else one second, and yet in complete unison the next. They are passing tape, scissors, or wire on demand. Someone says, "hold this" and a hand emerges to fill the need. Students working as distributors hand on the periphery waiting the few seconds it takes to fill a need, while cutting strips of tape or wire in preparation for the next demand. There is a furrowed brow, a zip tie waiting to be used between teeth, giggles, directives, and chatter. Work seems important, serious...but equally fun. 


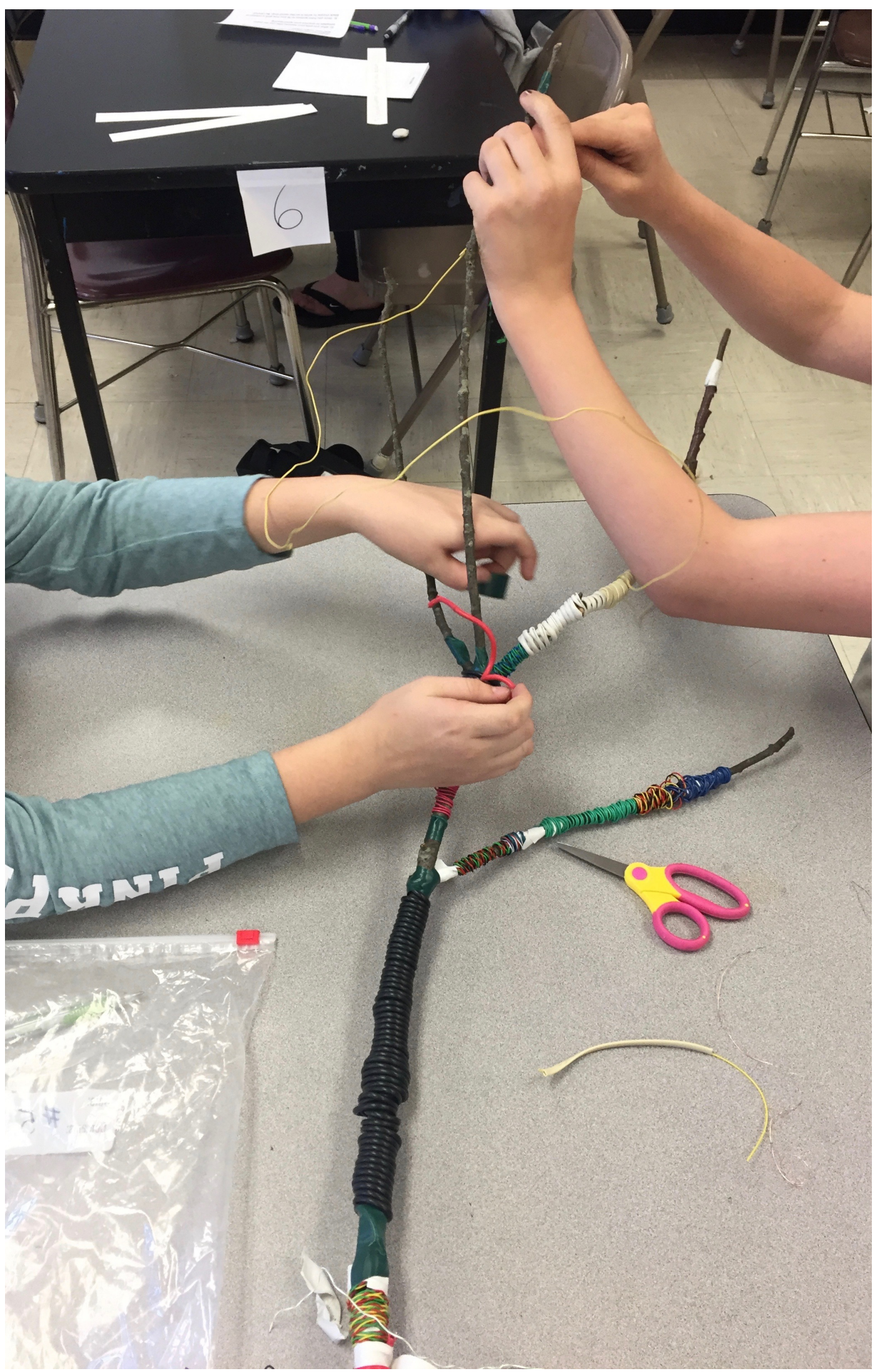

Figure 10. Two students work together to wrap a branch. 


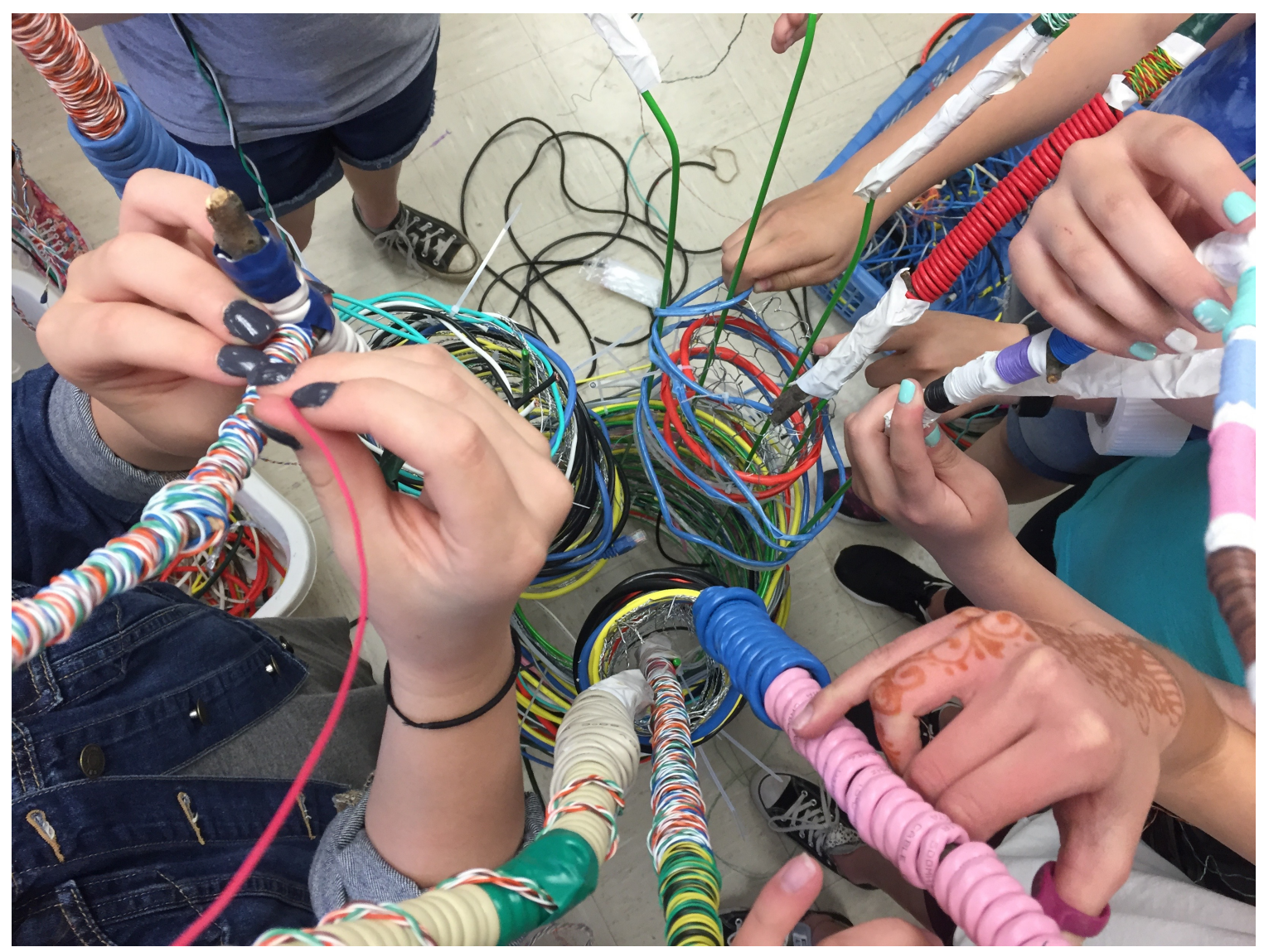

Figure 11. Several students work collaboratively to wrap the tree trunk and connect branches.

\section{Representing}

This project allowed students to physically represent an idea or concept through common materials, as a way to engage in contemporary artmaking processes. In the pre-questionnaire, given at the beginning of the research project, students mainly defined art as a way of selfexpression. A few students emphasized the importance of technical skill, the elements of art and principles of design, and art as product. One significant change in the definition of art, is reflected in Student 25's statements. Initially, Student 25 defined art as, "color put together to make something amazing," however, at the end of the two-weeks the student elaborated by further noting, "It can be something to prove a point...or political." 


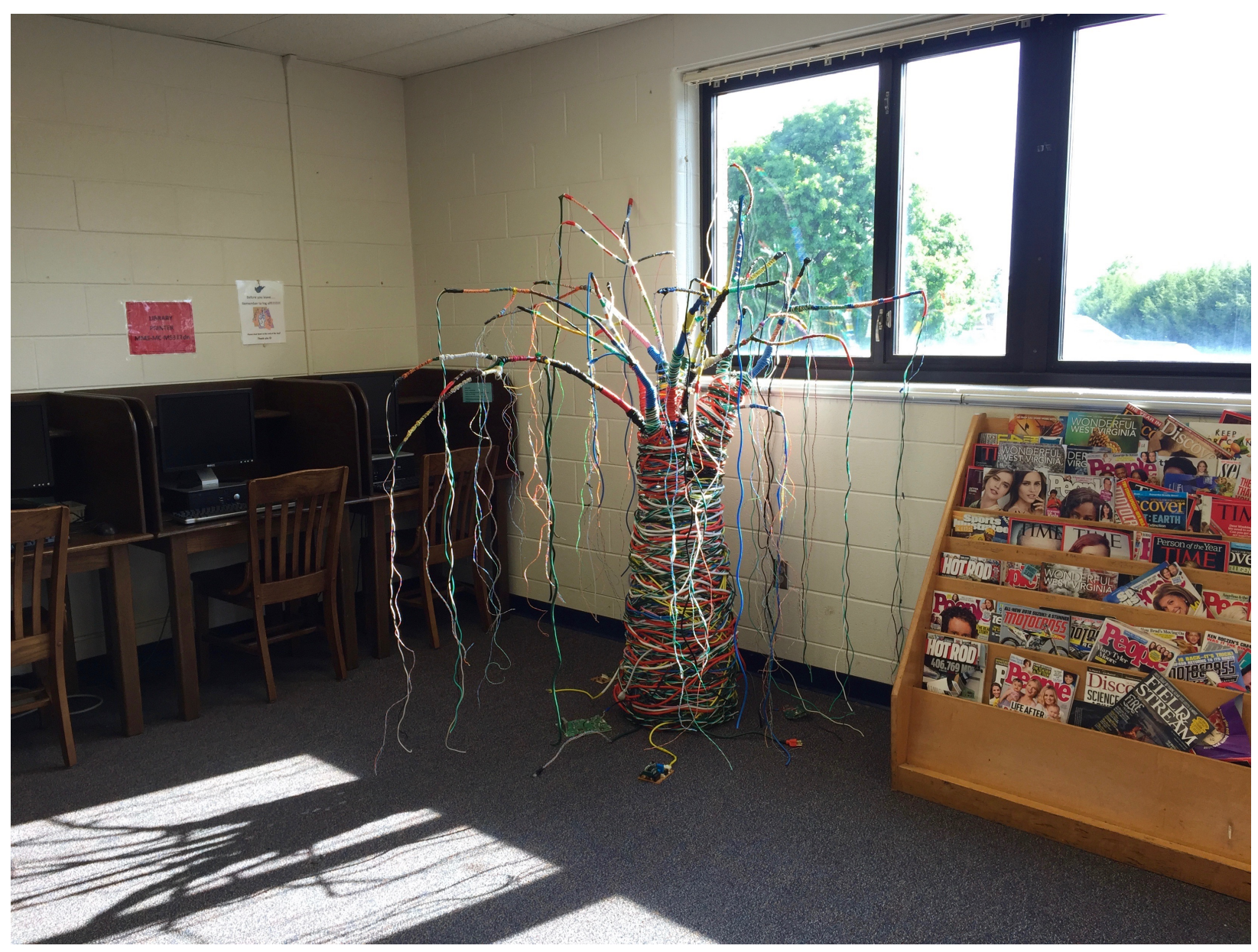

Figure 12. The completed wire willow tree displayed in the library. 


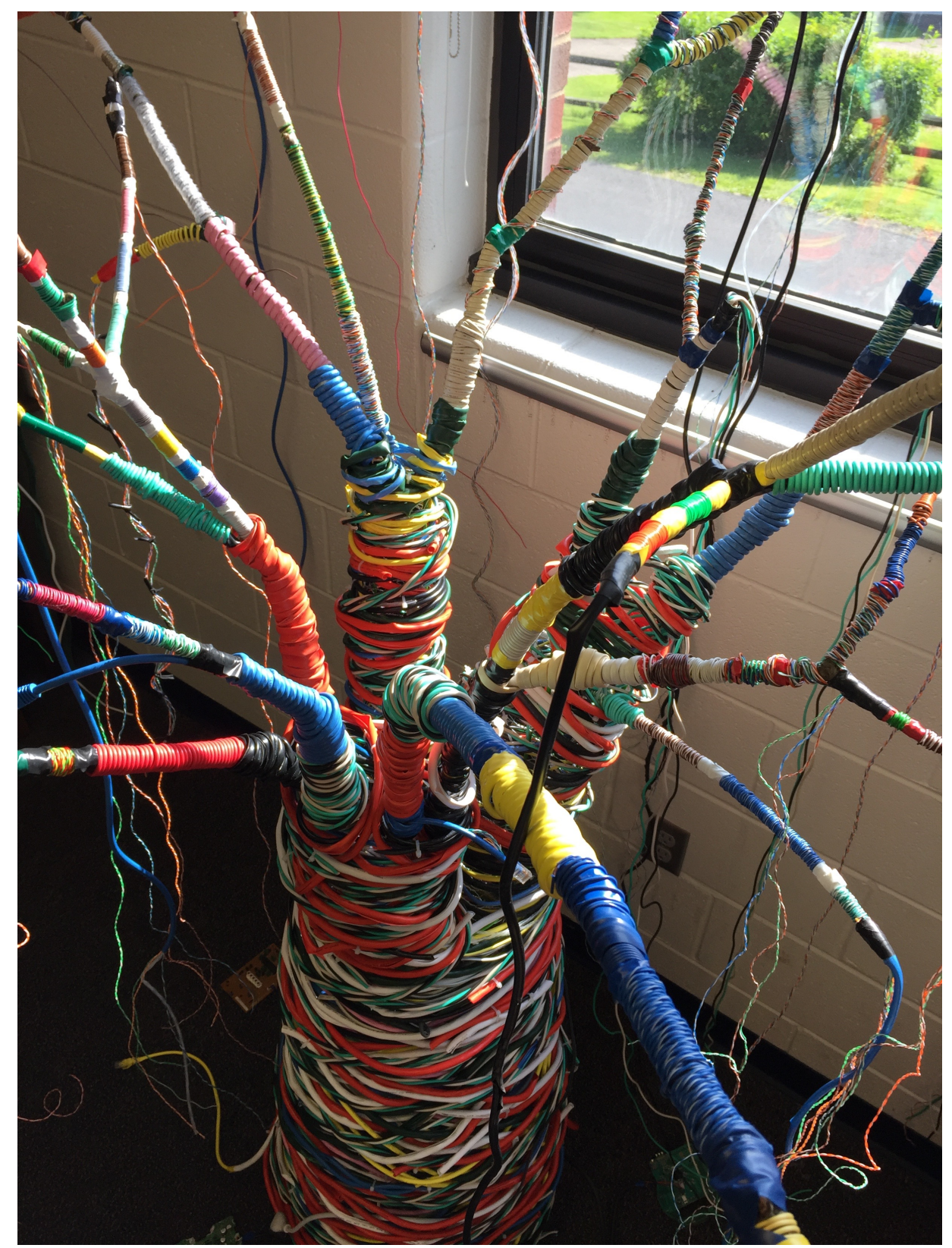

Figure 13. Detail of the completed wire willow tree, which is displayed in the library.

\section{Reflecting}

Students were often asked to reflect on the initial analysis of the material (i.e. electrical wire) toward further interpreting, questioning, and finding meaning (Figure 7). Reflecting on how we could further represent the idea of knowledge or power Student 6 suggested attaching 
electronic devices to the tree. Student 6's idea took shape through a thumbnail sketch session (Figure 14). According to Student 6 the idea was that, "our electronic devices connect us with the internet, and with our friends and family." After collectively discussing the logistics of acquiring electronic devices, the class decided that a few circuit boards collected from some broken or outdated electronics would illustrate the point or relay the meaning just as well (Figure 15).

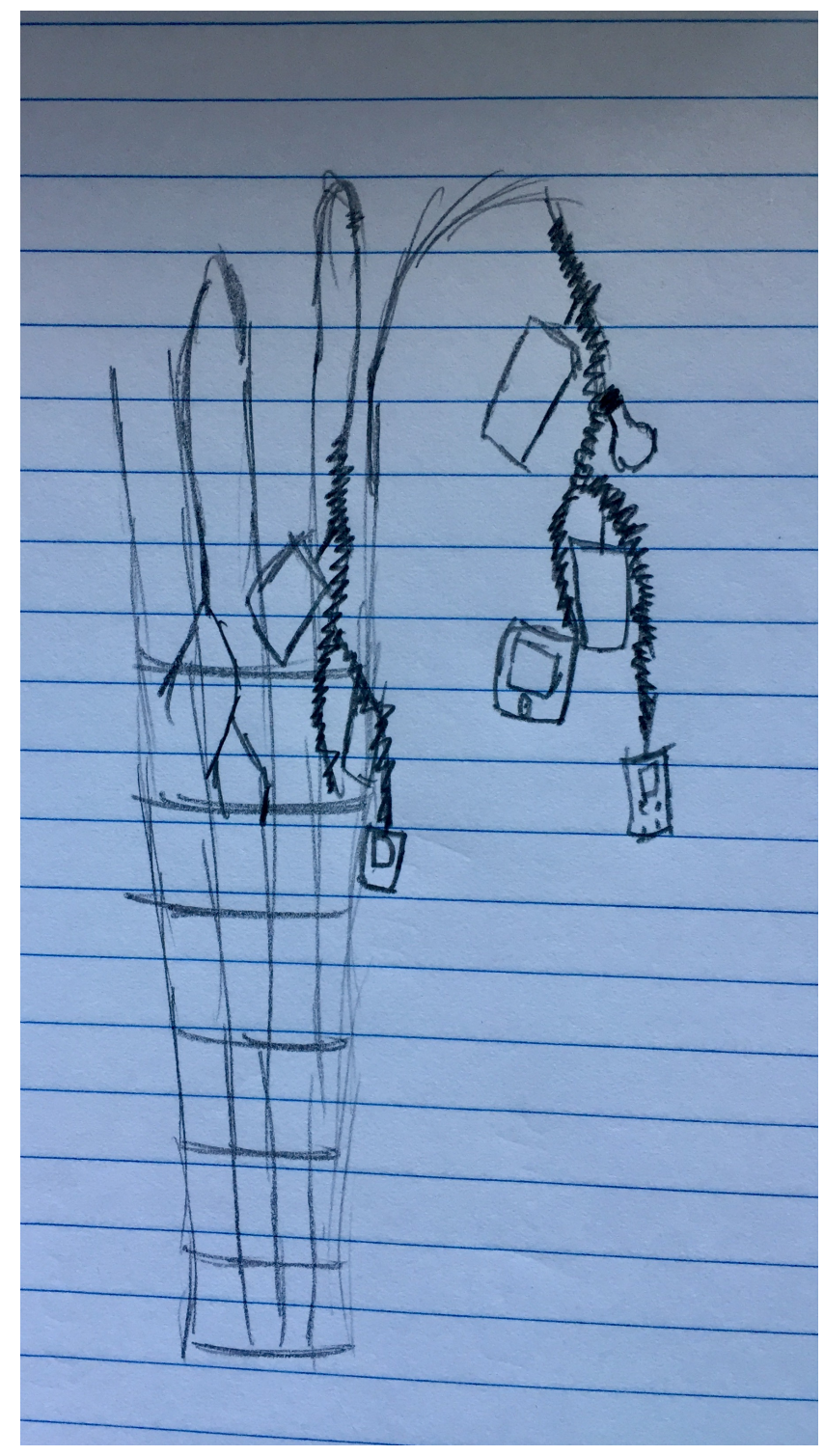

Figure 14. Student sketch of an idea to expand the project. 


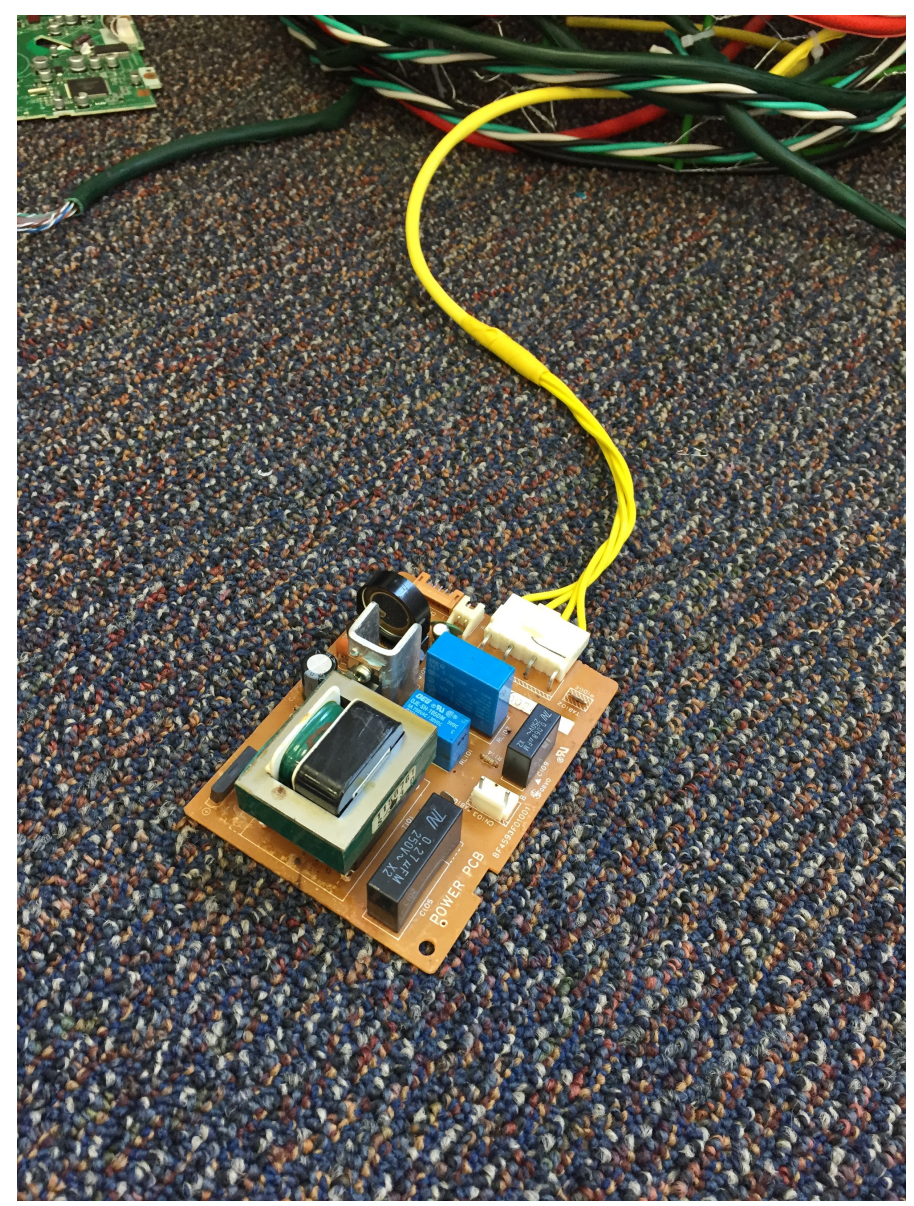

Figure 15. Representation implemented based on the idea presented by Student 6 .

\section{Connecting}

Analyzing everyday objects and contemporary artwork allowed students to make or recognize connections between objects or art and their own personal lives. To this end, students responded to visual or material culture in a personal and meaningful way, sometimes connecting feelings or senses to material objects (Figure 16). When asked how the earrings placed at her table made her feel, Student 3 responded, "they make me feel like me." I inquired further by asking, "So, when you look at these earrings they make you feel like...you?". She shrugged and went on to say, “I don't wear earrings, my ears aren't pierced...." She paused and then continued, "I feel hurt.". "Hurt?", I asked. Connecting this material with a physical sensation, she 
went on to say, "yeah, every time I get my ears pierced I cry." Immediately the student seated across from her eagerly inquired, “How many times have you gotten your ears pierced?'. Student 3 responded, "three times...." To which the neighboring student pointed out, "but they aren't pierced now." Student 3 simply said, "I know." It only took some deep looking and one guiding question from me to prompt this anecdote from Student 3, but these are the types of stories which Liza Lou admits are such a pleasure within her collaborative process (Hodara, 2016).

The analysis of electrical wire/cord also sparked very personal connections for several students. Student 2 connected the material to her father who works for an electric company. Additionally, Student 5 excitedly shared with me that his father used electricity to blow up rocks. He often discussed his basement, in which he and his father spent time working, and expressed a desire to bring in his own tools to cut and dissect wire. (I declined due to permission and safety.)

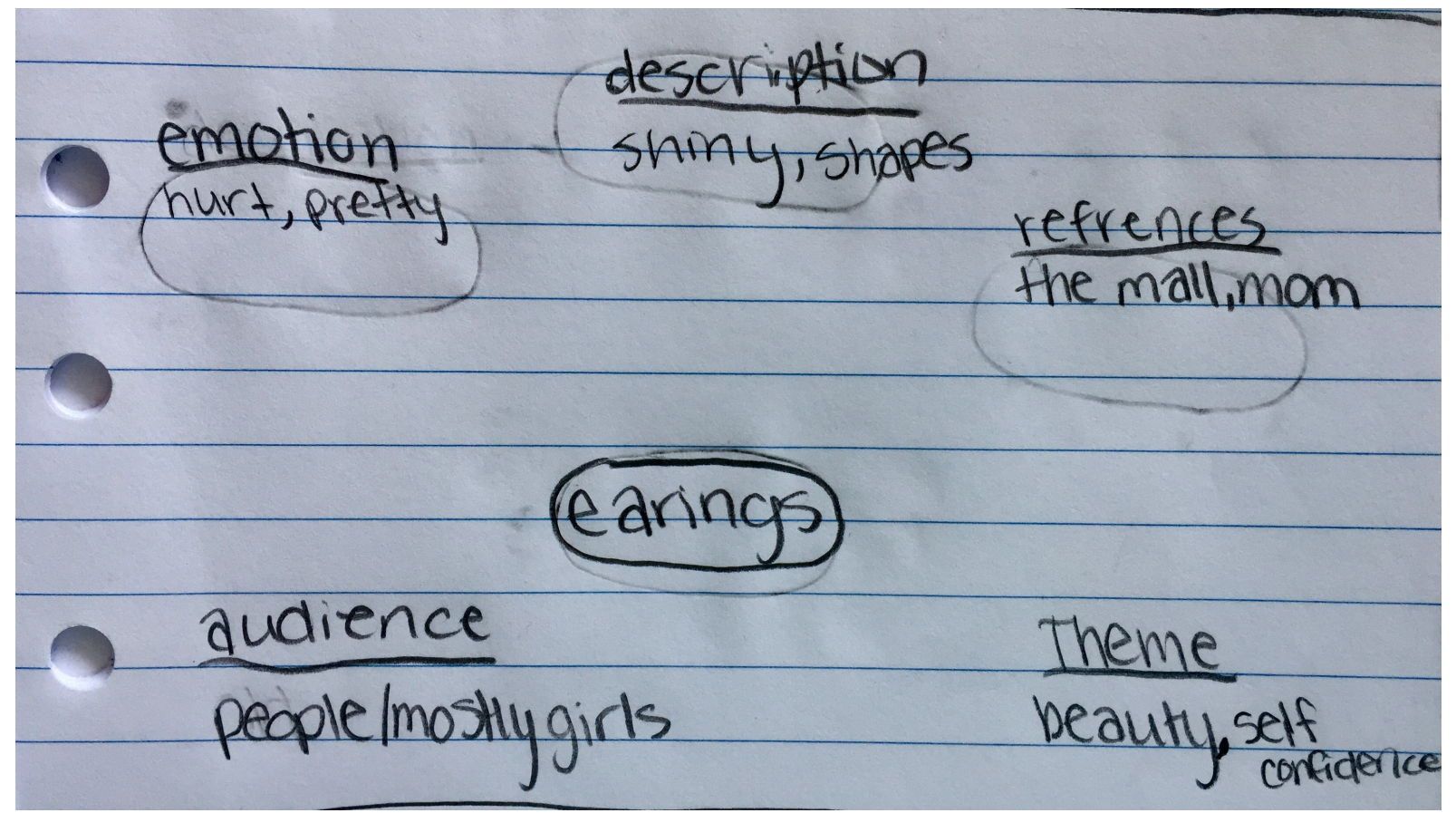

Figure 16. Student makes connections between earrings and pain or self-confidence. 


\section{Valuing}

Students were encouraged and allowed to choose their own preferred process, so some students worked diligently doing the same repetitive process (Figure 17). An excerpt from my field notes observes the variety of student activities and art-making processes happening simultaneously:

Several tables work collectively on one branch with little argument, while some students prefer to work on their own - sometimes due to disagreement, but mostly because they seem too focused on the task at hand to consider the practicality of another person wrapping the opposite end of the stick. At a table one girl is dissecting wire, one twisting, and one wrapping. Some students take special delight in ripping cords apart and are very anxious to get to the insides. Alternatively, some students find pleasure in braiding while they chat with a neighbor who holds the top end of the braid loyally.

One student in particular, Student 5, only uncased large extension cord-he loved it, he was good at it, and he felt it was his purpose. When presented with more extension cord to uncase one day, he stated, "I love doing this. If you gave me a hundred of these I would do it all day," to which I replied, "I know you are the expert at it, it's your thing." This student liked to work alone and worked very seriously while kneeling on the floor diligently deconstructing large (by comparison) extension cord.

Several students took pride in the physical discomfort resulting from laboriously uncasing thick extension cords. Within my journal, I note:

A couple of boys hold their palms up and rub them with their fingers, and share how the work hurts their hands. These boys move quickly and eagerly to the large cord at the beginning of every class. They willingly work with heavier duty tools and thicker cords...so they declare this with a bit of excitement and pride, as if working hard is something you can feel both internally and externally.

Other students jumped back and forth between different areas of construction: branch wrapping, willow making, trunk wrapping, uncasing, braiding, twisting, etc. 


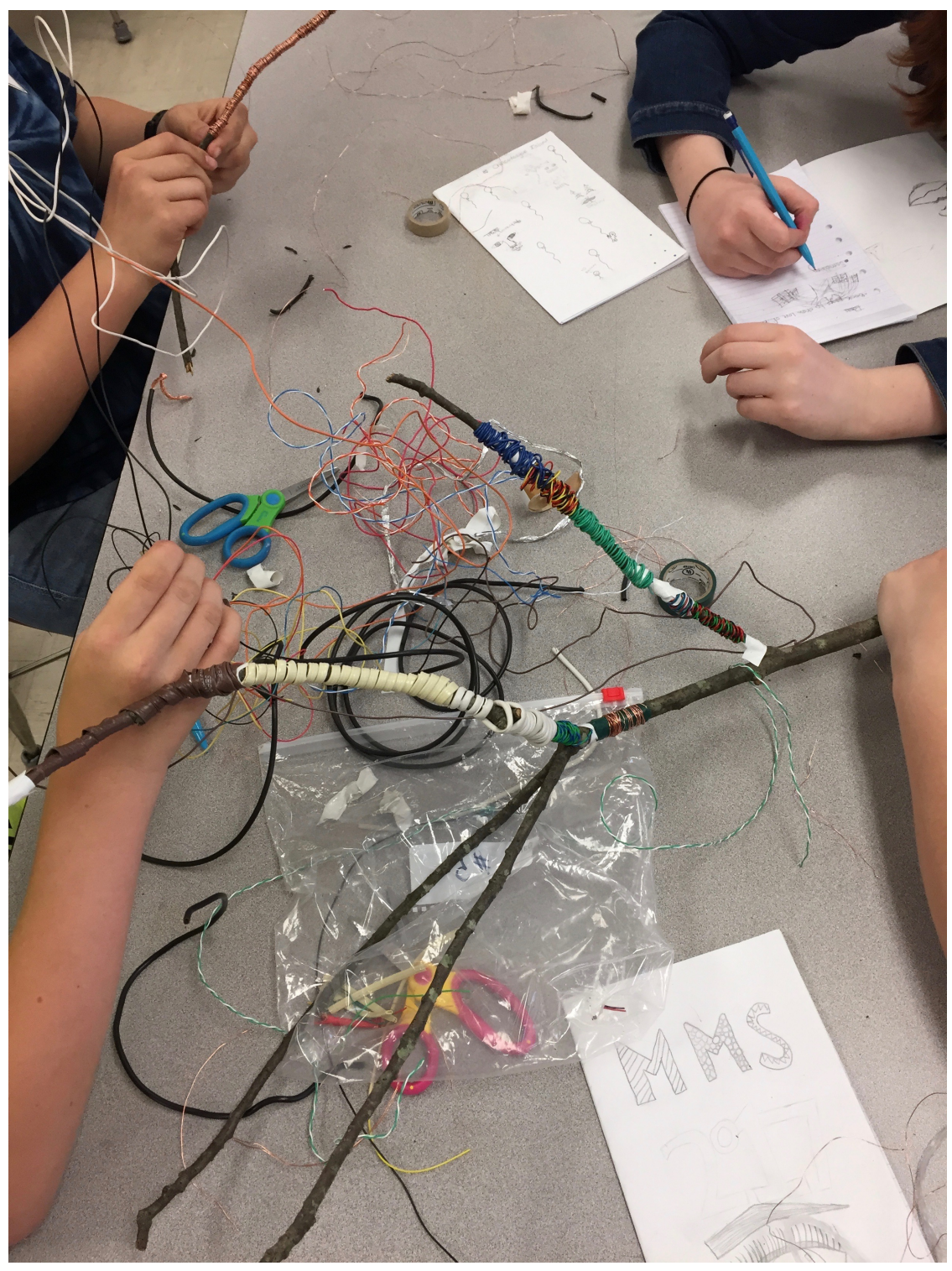

Figure 17. A student wrapping a branch independently, a student recording ideas, and a pair of students co-wrapping a single branch.

For Research Question 3, how do material culture lessons foster appreciation for everyday objects/ materials among middle school students, I used observational field notes, student journals/assignments, and a questionnaire. I utilized student journals/assignments and a post-questionnaire to gauge student's appreciation for everyday objects/materials. Journals and 
questionnaires were handwritten and thus required typing into a Word document. All text was then converted to a table for further coding.

After the students successfully analyzed a single common/everyday object, I presented a series of artwork which utilized common materials. The contemporary artwork captivated the students, and discussions arose about whether a slide of artwork was indeed art or not. Providing this time to analyze a single object guided students through the process of looking deeply, the first step towards appreciation (Dewey 2005). Students were energetic and eager to find out which object would be placed in front of their group.

When asked in the post-questionnaire if students developed an appreciation for everyday objects and materials all but three participants reported that the project did result in an appreciation. Student 13 wrote, "I realized objects can take you back to a time or place". Another student wrote, "Yes, it helped me see the value in everyday objects." Of the three students who reported they did not develop an appreciation they all stated it was because they already had an appreciation for everyday objects and materials and, therefore, nothing changed.

When asked if the students felt the materials used in this project were just as valuable as traditional art materials (paint, ink, clay) the large majority responded with, "yes". One student wrote, "Yes, because they [nontraditional materials] would have a deeper meaning than using just paint." Yet another student wrote, “They are just as valuable because they get the point across." Both students seem to imply that common materials are embedded with meaning and can be used as a strategy for communicating ideas. 


\section{Additional Findings}

\section{Disinterest \& Discomfort}

Some students may be disinterested in working on a collaborative project or uncomfortable working collaboratively. When working collaboratively individual ideas emerge during the brainstorming process of constructing knowledge, however, every individual's ideas will not be able to come to fruition given the nature of the project. Some students may become disinterested if their idea was not favored or followed through in the design of the project. Some amount of discomfort is often a normal feeling when a student is being challenged, which is a necessary component when learning something new. Some students may feel uncomfortable working in an unfamiliar medium, which may test their artistic confidence. Additionally, some students may feel uncomfortable working collaboratively or in partnerships due to their shy disposition. Working collaboratively requires direct communication and may often involve compromise, thus students, especially those who are shy or socially guarded may feel uncomfortable voicing their opinions or interacting in this manner.

\section{Time \& Space}

Within the field of art time and space are often desired and necessary, yet limited and thus problematic. This project, the production and process of making a collaborativelyconstructed and three-dimensional artwork, reflected the general time and space limitations deemed characteristic within the arts. Time allotted for the project was limited to two weeks, consisting of ten 40-minute class periods. Due to the time constraints, as well as the nature of much contemporary art, a collaborative approach was implemented. A collaborative approach distributes responsibility and evades total individual accountability, so much as it may inhibit the 
completion of the project. In this way time was made more malleable and could be managed more holistically.

Time was limited and thus necessitated a focus on depth versus breadth in-regard-to the variety of material culture addressed within the two-week lessons. Two-weeks is not sufficient time to investigate and engage both cognitively and physically with a wide variety of common materials in a deep and rich manner. I believe depth is superior to breadth, however, due to time constraints the study was limited to concentrated depth, regardless of my opinion or preference.

Space proved problematic due to a few unavoidable factors. First, the space in which we worked was not my own, but my cooperating teacher's classroom. The project was limited due to borrowed space for both creating and exhibiting works. Space is precious within an art classroom, as storage for art supplies and works in progress are often in conflict with areas of clean and clear surface space required for creating. Due to the nature of the project, material culture, I allowed for the creation of something relatively monumental in scope, yet feasible for in-process working and storage, as well as exhibiting. The finished piece is relatively large and could potentially obstruct general traffic flow or educational space, however, it stands alone without requiring any support or attachments which would likely inhibit easy relocation to accommodate the spatial needs of the student body, administration, or other educators. 


\section{CHAPTER SIX}

\section{Findings}

The purpose of this study was to examine the use of material culture lessons towards cultivating artistic behaviors and enriching middle-level students' perceptive and conceptual understanding in a contemporary educational context. The findings appear to suggest improvements in students' understanding of contemporary art and appreciation for everyday materials/objects, as well as a comprehensive engagement with artistic behaviors. A summary of the findings, interpretation of the findings, and suggestions for future research are presented in this chapter.

From the research questions, the following emerged:

\section{Material culture lessons can promote middle school students' understanding of} contemporary art, can support artistic behavior, and can foster appreciation for everyday objects/materials. Through data, analysis, and findings it seems this study provides a way to combat the issue of the increasingly underfunded and undervalued arts by engaging students in contemporary artmaking processes through inexpensively collected common materials. The case study of a middle school art class provided an example of how material culture can be utilized to support understanding of contemporary art, promote artistic behavior, and foster an appreciation of everyday objects and materials. The findings, resulting from the case study, appear to suggest improvements in students' understanding of contemporary art and appreciation for everyday materials/objects, as well as a comprehensive engagement with artistic behaviors. The collected data supported how these findings emerged through a case study approach using qualitative data.

For Research Question 1, (how do material culture lessons promote student understanding of contemporary art in a middle school art class), my findings appear to suggest 
that the material culture lessons overall promoted student understanding by scaffolding student analysis and discussion of contemporary art. Additionally, my findings show that the material culture lessons engaged students in art-making processes critical toward understanding how contemporary art is created. Student responses reflected an understanding that form, and more importantly meaning, often follow material within the contemporary art-making process.

For Research Question 2, (how do material culture lessons support artistic behavior among middle school students), my findings appear to suggest that material culture lessons overall proved to be supportive by comprehensively engaging students in the nine artistic behaviors outlined within the literature review. The data collected showed that students engaged in a range of artistic behaviors throughout the two-week long lessons. Engaging with artistic behaviors often resulted in further understanding of contemporary art and common materials. Overlapping facets, which proved supportive of student comprehensive understanding, will also be addressed. The fluidity of the findings supports the notion of blurred boundaries, a common feature in contemporary education.

The findings appear to show significant engagement with the following behaviors:

\section{Problem Finding}

My findings appeared to show that problem finding was a behavior which was supported throughout the lessons. Students engaged in problem finding when presented with a variety of materials and objects in which to analyze and interpret meaning. The predominate material additionally supported problem finding behaviors, as students sought to infer meaning in the development of a key idea or theme. 


\section{Problem Solving}

Data collected showed that problem solving was a significant artistic behavior frequently employed. The predominate material within the project was unfamiliar to students, as well as myself, in the context of art-making. Unlike media within the canon, untraditional or common materials do not come with suggestions for use in art-making or technical implications, as do watercolor or charcoal. Electrical cords/wires were not designed with art-making in mind, so students were left to discover successful and unsuccessful ways of working with the material. Data collected appears to show that artmaking with common materials, versus traditional materials, negates the teacher explicitly 'banking' procedures and methods and allows students to self-direct discovery and problem solve accordingly.

\section{Planning}

Data collected suggested a strong use of student planning, which proved crucial throughout the project's conception, creation, and completion. Planning, a subcategory of working habits, was made visible through brainstorming, sketching, and class discussions. Planning proved most significant when discussing the logistics of relocating the tree from the second-floor of the school to the first-floor library, which required attention to at least three doorways. Planning, in this case, overlaps with problem solving.

\section{Collecting}

Collecting, a subcategory of working habits, was critical to the project. The project required students to collect materials necessary for completing the final form. By collecting common materials, students extended an artistic behavior beyond the school setting by canvasing their homes for electrical cords/wires. The act of collecting common 
materials outside of the art classroom allowed students' everyday lives and built environment to become relevant to art-making. This allowed art to come into the home and the home to come into the art, thus, further blurring compartmental boundaries. Furthermore, the act of collecting unwanted or discarded common materials allowed students to experience contemporary artistic processes toward deeper understanding.

\section{Collaborating}

My findings showed that collaborating, a subcategory of working habits, proved to be a significant artistic behavior. Students consistently collaborated on activities involving both cognition and physical engagement. Students often collaboratively constructed knowledge by sharing ideas through discussions and brainstorming sessions. Furthermore, collaboration provided a way for students to teach other students their selfdiscovered solutions and/or findings, as well as to become a sort of expert on a specific process (i.e. uncasing electrical cord). Additionally, students worked collaboratively to physically create the wire wrapped tree, attach branches, and connect vines. Lastly, collaboration between myself and the students provided a way for experts and novices to work simultaneously without the typical authoritative barrier commonly established between teacher and student. Collaborating and assisting students in the art-making process allowed me to work in unison and gain perspective into student experiences. Furthermore, data collected suggests that the student/teacher equilibrium established during the art-making process allowed for student ownership of duties, as well as studentdirected art-making. 
For Research Question 3, (how do material culture lessons foster appreciation for everyday objects/materials among middle school students), my findings appear to suggest that material culture lessons foster appreciation for everyday objects/materials by providing opportunities for students to perceive and investigate common materials meaningfully. Time specifically devoted to looking deeply at common materials (with teacher scaffolding) allowed students to make meaningful inferences, as well as personal connections. The emergence of meaningful and personal connections, after teacher prompting, to everyday objects/materials appears to suggest that a deeper appreciation was fostered among the students. Additionally, student appreciation was fostered through material culture by facilitating an opportunity to create contemporary art from common materials.

Further research should be done to investigate how exposure to material culture art lessons, using nontraditional materials, may affect the type and scope of student chosen materials for future art-making endeavors. Exposure to contemporary art and art-making with common materials may influence students' material choices in future art-making endeavors. Further research on material culture should focus more specifically on material choice, both individual and collaborative, within the middle school art classroom. Though one study did appear to suggest that material choice led to more meaningful artwork, the resulting form or product was predetermined by the educator (McElhany, 2017). In this case, a mask. Further research should be done to investigate how material choice, of common materials in art-making, may dictate or direct form. The final physical form of the collaborative project in this study was conceived by students in the classroom. However, additional research investigating how student chosen 
materials affect final representation or form could fill the gap between the literature review and this study on how material culture lessons can benefit student learning. 


\section{References}

Adams, M., Foutz, S., Luke, J., \& Stein, J. (2007). Thinking through art: Isabella stewart gardner museum school partnership program 3 three research results. Institute for Learning Innovation.

Ault, A. (2015, November 24). Artist chakaia booker gives tires a powerful retread. Retrieved from http://www.smithsonianmag.com/smithsonian-institution/artist-chakaia-booker gives-tires-powerful-retread-180957362/.

Baxter, K. (2014). A convergence of three: The reflexive capacity of art practice, curriculum design, and pedagogy. Art Education, 67(6), 28-34.

Berk, S. (2015) Using literature to activate critical intention in secondary student art. Art Education, 68(5), 6-12.

Blair, E. (2015, November 13). This Art Exhibit Makes You 'Wonder' - And That's The Whole Point. Retrieved from http://www.npr.org/2015/11/13/455751386/this-artexhibit-makes you-wonder-and-thats-the-whole-point

Blandy, D., \& Bolin, P. (2012). Looking at, engaging more: Approaches for investigating material culture. Art Education 65(4), 40-46.

Bolin, P., \& Blandy, D. (2003). Beyond visual culture: Seven statements of support for material culture studies in art education. Studies in Art Education 44(3), p. 246-263.

Bolin, P., \& Blandy, D. (2011). Matter matters: Art education and material culture studies. Reston, VA: National Art Education Association.

Booker, C. (Sculptor). (2015). Anonymous Donor. [Dissected rubber tires reconstructed]. Retrieved from http://www.smithsonianmag.com/smithsonian-institution/artist-chakaia booker-gives-tires-powerful-retread-180957362/.

Bowen, D. H., Greene, J. P., \& Kisida, B. (2014). Learning to think critically: A visual art experiment. Educational Researcher, 43(1), 37-44.

Bowley, G. (2015, November 12). Smithsonian's Renwick Gallery Reopens With a New Focus. Retrieved from https://www.nytimes.com/2015/11/13/arts/design/smithsonians-renwick gallery-reopens-with-a-new-focus.html?_r=2.

Bransford, J.D., Brown, A.L. \& Cocking, R.R. (2000). How people learn. Washington: National Academies Press.

Cooper, D., Friedman, T., Hainley, B., \& Searle, A. (2003). Tom Friedman. London: Phaidon Press. 
Csikszentmihalyi, M. (1993). Why we need things. In S. Lubar 8c W. D. Kingery (Eds.), History from things: Essays on material culture (p. 20-29). Washington, DC: Smithsonian Institution Press.

Danto, A. (2009). On the being of being an artist: The gap between art and life. In Jacob, M.J. \& Baas, J. Learning mind: Experience into art. Chicago, Ill.: School of the Art Institute of Chicago.

Denzin, N. K., \& Lincoln, Y. S. (2013). Strategies of qualitative inquiry. Thousand Oaks, CA: SAGE.

Dewey, J. (2005). Art as Experience. New York: Penguin Group. (Original work published 1934)

Donovan, T. (Sculptor). (2014). Untitled. [Stacked index card installation]. Retrieved from http://americanart.si.edu/exhibitions/online/wonder/donovan.cfm

Douglas, K.M., \& Jaquith, D.B. (2009). Engaging learners through artmaking: Choice based art education in the classroom. New York: Teachers College Press.

Duchamp, M. (Artist). (1917/1964). Fountain [Signed and dated porcelain urinal]. Retrieved from http://www.tate.org.uk/art/artworks/duchamp-fountain-t07573.

Duncum, P. (2012). An eye does not make an i: Expanding the sensorium. Studies in Art Education, 53(3), p 182-193.

Efland, A. (1976). The school art style: A functional analysis. Studies in Art Education, 17(2), $37-44$.

Eisner, E. (2002). The arts and the creation of mind. New Haven: Yale University Press.

Flick, U. (2009). An introduction to qualitative research: UWE Flick (4th ed.). Los Angeles: SAGE.

Franco, M., Ward, A., \& Unrath, K. (2015). Artmaking as meaning-making: A new model for preservice elementary generalists. Art Education 68(5), 28-33.

Freedman, K. (2003). Teaching visual culture curriculum, aesthetics and the social life of art. New York: Teachers College Press.

Friedman, T. (Sculptor). (1995). Untitled. [Toothpick starburst]. Retrieved from http://www.saatchigallery.com/aipe/tom_friedman.htm

Graham, M. A., \& Zwirn, S. G. (2010). How being a teaching artist can influence K-12 art education. Studies in Art Education, 51(3), 219-232. 
Greene, J. P., Kisida, B., \& Bowen, D. H. (2014). The educational value of field trips. Education Next, 14(1).

Grodoski, C. (2016). Unpacking \& packing visual culture: Creative thinking strategies. Art Education, 69 (3), 20-26.

Gude, O. (2010). Playing, creativity, possibility. Art Education, 63(2), 31-37.

Gude, O. (2004). Postmodern principles: In search of a $21^{\text {st }}$ century art education. Art Education, 57(1), 6-14.

Hathaway, N.E. (2013). Smoke and mirrors: Art teacher as magician. Art Education, 66(3), 9-15.

Heartney, E. (2008). Art \& today. London: Phaidon Press.

Hetland, L., Winner, E., Veenema, S., Sheridan, K. (2013). Studio thinking 2: The real benefits of visual arts education, second edition. New York: Teachers College Press.

Hodara, S. (2016, January 02). Liza lou's handmade sea of sparkling glass. Retrieved from https://www.nytimes.com/2016/01/03/nyregion/liza-lous-handmade-sea-of-sparkling glass.html?_r=0.

Holt, S. S., \& Skov, M. H. (2008). Manufractured: the conspicuous transformation of everyday objects. San Francisco, CA: Chronicle Books.

Joo, E., Keehn, J., \& Ham-Roberts, J. (2011). Rethinking contemporary art and multicultural education, second edition. New York: Routledge.

Kee, J.B., Bailey C., Horton S., Kelly K., et all. (2016). Art at ashé: Collaboration as creative assemblage. Arts Education 69(5), 14-19.

Leake, M. (2014). Social engagements with contemporary art: Connecting theory with practice. Art Education, 67(5), 23-30.

Learning with Art21 Guide. (n.d.). Retrieved from https://art21.org/for-educators/tools-for teaching/guides/learning-with-art21-guide/.

Lou, L. (Sculptor). (2015). Color Field [Tiles of blades made from wires and glass beads]. Retrieved from https://www.nytimes.com/2016/01/03/nyregion/liza-lous-handmade-sea of-sparkling-glass.html?_r=0.

Mayot, R. (Sculptor). (2008). Mines [Patches of plastic recomposed into a form]. Retrieved from http://museumofcontemporarycraft.org/manufractured/artists/mayot.html.

McElhany, J.S. (2017). Awakening student ownership: Transitioning to a student-centered 
environment. Art Education 70, (1), 29-35.

Miraglia, K. M., \& Smilan, C. (2014). Inquiry in action: Paradigms, methodologies, and perspectives in art education research. Reston, VA: National Art Education Association.

Museum of Contemporary Art San Diego. (2013, July 12). Liza Lou - color field. [Video File]. Retrieved from https://www.youtube.com/watch?v=OH-99UF9bms.

NAEP Arts Assessment. (2016). Retrieved from https://www.arteducators.org/research/naep arts-assessment

Newman, F. M., \& Wehlage, G. G. (1993). Five standards of authentic instruction. Authentic Learning, 50(7), 8-12.

Pavlou, V. (2009) Understanding young children's three-dimensional creative potential in art making. International Journal of Art \& Design Education, 28(2), 139-50.

Perkowski, L.M. (2015) Processing film processing meaning. Art Education, 68(3), 32-38.

Ridge, A. G. (2015). New Genres in the Art Classroom: Shifting Ideas and Identities. Retrieved from http://scholarsarchive.byu.edu/etd/5789/.

Robson, C. (2009). Real world research: A resource for social scientists and practitioner researchers. Malden, MA: Blackwell.

Serig, D. (2011). Of matter and metaphor: Travel, purchases, and personal identity. In P.E. Bolin \& D. Blandy (Eds.), Matter matters: Art education and material culture studies (p. 47 55). Reston, VA: National Art Education Association.

Smith, D.L. (2011). Material culture and issues-based art education. International Journal of Art Education, 9(2), 92-100.

The Right Stuff: Tara Donovan is the Ultimate Material Girl. (2011). Retrieved May from http://www.pacegallery.com/news/203/the-right-stuff-tara-donovan-is-the ultimate-material-girl

Thompson, C.M. (2015). Constructivism in the art classroom: Praxis and policy. Arts Education Policy Review, 3(116), 118-127.

Thulson, A. (2013) Contemporary practice in the elementary classroom: A study of change. Art Education, 66(1), 16-23.

U.S. Department of Education, Institute of Education Sciences, National Center for Education Statistics, National Assessment of Educational Progress (NAEP), 2008 Arts Assessment.

Villeneuve, P., \& Erickson, M. (2008). The trouble with contemporary art is... Art Education, 
61(2), 92-97.

Witmer, S., Luke, J., \& Adams, M. (2000). Exploring the potential of museum multiple-visit programs. Art Education, 53(5), 46-54. 


\title{
WestVirginiaUniversity. \\ Office of Research Integrity and Compliance \\ 886 CHESNUT RIDGE ROAD MORGANTOWN, WV 26506
}

Approval Letter Expedited

\author{
Action Date \\ $02 / 24 / 2017$ \\ To \\ Terese Giobbia \\ From \\ WVU Office of Research Integrity and Compliance \\ Approval Date \\ $02 / 23 / 2017$ \\ Expiration Date \\ $02 / 22 / 2018$ \\ Subject \\ Protocol Approval Letter \\ Protocol Number \\ 1702446246 \\ Title \\ Material Culture and Contemporary Art: A Middle School Case Study
}

The above-referenced research study was reviewed by the West Virginia University Institutional Review Board IRB and was approved in accordance with 46 CFR $46.101 \mathrm{~b}$.

It has been determined that this study is of minimal risk and meets the criteria as defined by the expedited categories listed below:

- Category 7. Research on individual or group characteristics or behavior (including, but not limited to, research on perception, cognition, motivation, identity, language, communication, cultural beliefs or practices, and social behavior) or research employing survey, interview, oral history, focus group, program evaluation, human factors evaluation, or quality assurance methodologies. [NOTE: Some research in this category may be exempt from the DHHS regulations for the protection of human subjects. See Exempt Categories and 45 CFR 46.101(b)(2) and (b)(3). This listing refers only to research that is not exempt.]

Documents reviewed and/or approved as part of this submission:

Principal_Permission_IRB.pdf: 2017-02-01-05:00

Assent_IRB_Turner.pdf: 2017-02-15-05:00

Consent_IRB_Turner.pdf: 2017-02-15-05:00

CoverLetter_IRB_Turner.pdf: 2017-02-15-05:00

Prompts:Questions_Turner.pdf: 2017-02-15-05:00 
Documents for use in this study are available in the WVUkc system in the Notes and Attachments section of your protocol.

The Office of Research Integrity and Compliance is here to provide assistance to you from the initial submission of an IRB protocol and all subsequent activity. Please feel free to contact us by phone at 304.293.7073 with any question you may have. Thank you.

WVU Office of Research Integrity and Compliance

Date:02/24/2017

Signed:

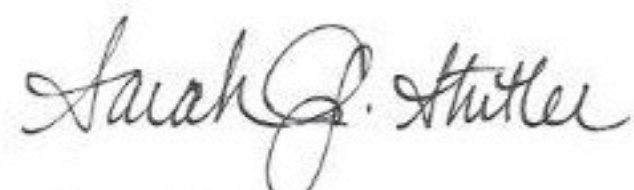

\section{Sarah Stutler}

IRB Administrator

ving regulations apply:

1. Unanticipated or serious adverse events/side effects encountered in this research study must be reported to the IRB within five (5) days via the Notify IRB action.

2. Any modifications to the study protocol or informed consent form must be reviewed and approved by the IRB prior to implementation via submission of an amendment.

3. You may not use a modified informed consent form until it has been approved and validated by the IRB. 
APPENDIX B

\section{W- WestViriginiaUniversity.}

Human Research Protocol

Only Minimal Risk Consent

Parental or Guardian

(Without HIPAA)

\begin{tabular}{|c|c|}
\hline & $\begin{array}{c}\text { Only Minimal Risk } \\
\text { Parental or Guardian Consent (Without HIPAA) }\end{array}$ \\
\hline Principal Investigator & Dr. Terese Giobbia \\
\hline Department & Art and Design \\
\hline Protocol Number & 1702446246 \\
\hline Study Title & Material Culture and Contemporary Art: A Middle School Case Study \\
\hline Co-Investigator(s) & Emily Turner \\
\hline
\end{tabular}

\section{Contact Persons}

If you have any questions, concerns, or complaints about this proposed research, you can contact Dr. Terese Giobbia at (304) 293-2393 or Emily Turner at (865) 388-8491.

For information regarding your child's rights as a research participant, to discuss problems, concerns, or suggestions related to the proposed research, to obtain information or offer input about the proposed research, contact the Office of Research Integrity and Compliance (304) 293-7073.

\section{Introduction}

Your child, has been asked to participate in the proposed research, which has been explained to you and your child by Dr. Giobbia and Emily Turner. This study is being conducted by Dr. Terese Giobbia (BS in Art, MS \& Ph.D. in Art Education) and Emily Turner (BFA in Fine Art and seeking an MA in Art Education) in the Department of Art and Design at West Virginia University. The proposed research is being conducted to fulfill the requirements for a master's thesis in Art Education in the Department of Art and Design at West Virginia University, under the supervision of Dr. Terese Giobbia.

\section{Purpose(s) of the Study}

As you know, West Virginia University is a research university. As part of my master's thesis, I would like to take photos of your child's artwork and obtain copies of their course work to better evaluate the effectiveness of teaching contemporary art and practices through the material culture lessons I will be implementing as your child's student teacher. Material culture art lessons are lessons which involve engagement and appreciation of everyday, or man-made, objects and materials, rather than traditional artmaking materials such as: paint, ink, charcoal, or clay. These lessons will

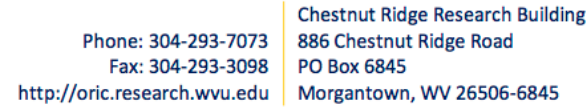

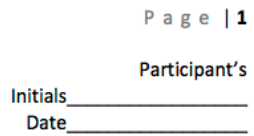




\section{WestVirginiaUniversity.}

\section{Human Research Protocol \\ Only Minimal Risk Consent \\ Parental or Guardian \\ (Without HIPAA)}

engage participants in inquiry and interpretation of everyday objects and materials through discussion and journal prompts, as well as contemporary artmaking processes.

\section{Description of Procedures}

The proposed research will include observation of your child's engagement in his/her daily learning activities, photos of their artwork and course work, as well as analysis. This will not require your child to do anything above and beyond what they would be doing in class anyway. If you choose not to allow your child to participate, s/he will remain in their classroom and continue the exact same lesson, but their work will not be photographed and copies of their course work will not be analyzed.

The proposed research will be performed at Mountaineer Middle School. Approximately $\mathbf{3 0}$ subjects are expected to participate in the proposed research. Your child will be observed in their normal classroom during normal course activities. It is estimated that the research study will take approximately 2 weeks to complete. At no time will your child be separated from peers or the teachers.

\section{Risks and Discomforts}

There are no known or expected risks to your child from participating in this study, except your child may feel uncomfortable having their work photographed. However, your child's name, face, or any other identifiable information will not be captured. You can ask for your child to not participate at any time. Your child may also ask not to participate at any time. You are able to remove your child from the study at any time and your child will continue to receive quality arts instruction in this classroom.

\section{Alternatives}

Your child does not have to participate in the proposed research. If your child does not participate in the proposed research he/she will continue the normal coursework and his/her grade will not be affected.

\section{Benefits}

There will be no direct benefit to your child from participating in the proposed research. However, the information gained from the proposed research may help education professionals better understand how students can learn from material culture art studies.

\section{Financial Considerations}

No payments will be made for participating in the proposed research.

\section{Confidentiality}

Any information about your child that is obtained as a result of their participation in the proposed research will be kept as confidential as legally possible.

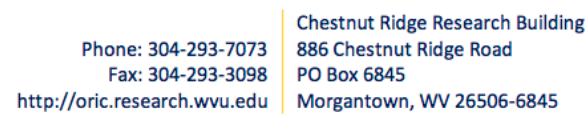

Chestnut Ridge Research Building

Morgantown, WV 26506-6845
Pag e | 2

Participant's

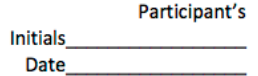




\section{WestViriniaianiversity.}

\author{
Human Research Protocol \\ Only Minimal Risk Consent \\ Parental or Guardian \\ (Without HIPAA)
}

Reasonable efforts will be made to keep the personal information in your research record private and confidential. Any identifiable information obtained in connection with the proposed research will remain confidential and will be disclosed only with your permission or as required by law. The members of the research team and the West Virginia University Office of Research Compliance (ORC) may access the data. The ORC monitors research studies to protect the rights and welfare of research participants.

Your name or your child's name will not be used in any written reports or publications which result from the proposed research, rather a pseudonym. Data will be kept for three years (per federal regulations) after the proposed research is complete and then destroyed.

\section{Voluntary Participation}

Refusal to participate or withdrawal will not affect your child's future education or grade.

\section{Signatures}

Upon signing this consent, you will receive a copy.

I willing consent to allow my child to participate in the proposed research.

Signature of Parent or Guardian

\begin{tabular}{lll}
\hline Printed Name & Date & Time
\end{tabular}

Signature of Investigator or Co-Investigator

$\begin{array}{lll}\text { Printed Name } & \text { Date } & \text { Time }\end{array}$

Chestnut Ridge Research Building

Phone: 304-293-7073 886 Chestnut Ridge Road

Fax: 304-293-3098 PO Box 6845

http://oric.research.wvu.edu Morgantown, WV 26506-6845
$P$ a g e $\mid \mathbf{3}$

Participant's 